\title{
El carácter dialógico del proceso con reconocimiento de responsabilidad ante la Jurisdicción Especial para la Paz: retos del derecho penal en contextos de justicia transicional*
}

\author{
The Dialogic Character of the Process in Cases of Recognition of Responsibility before the Special Jurisdiction for \\ Peace: Challenges for the Criminal Law in Transitional Justice Contexts
}

Gustavo Emilio Cote Barco a

Pontificia Universidad Javeriana, Colombia

gcote@javeriana.edu.co

DOI: https://doi.org/10.11144/Javeriana.vj69.cdpr

ORCID: https://orcid.org/0000-0002-1060-1622

Recepción: 07 Octubre 2019

Aceptación: 21 Octubre 2019

Publicación: 30 Junio 2020

\section{Resumen:}

El presente artículo pretende determinar qué significado puede tener el principio dialógico en el proceso con reconocimiento de responsabilidad en la Jurisdicción Especial para la Paz (JEP), así como explorar posibles implicaciones y dificultades de su concreción. El argumento central es que el principio dialógico constituye un aspecto directamente relacionado con la estructura y el alcance de este proceso, cuyas implicaciones reales aún están por definirse. Sin embargo, la manera como esto ocurra tendrá consecuencias sobre la medida en que se responderá a las expectativas de las víctimas. Las principales dificultades parecen obedecer, en todo caso, a los diferentes objetivos que en este contexto se persiguen con el proceso, dado su carácter penal, restaurativo y transicional, y a las tensiones que surgen entre ellos.

Palabras clave: proceso penal, justicia transicional, Jurisdicción Especial para la Paz, principio dialógico.

\section{Abstract:}

This article aims to establish the meaning that the dialogic principle has in criminal prosecution before the Special Jurisdiction for Peace, when the defendant accepts responsibility, as well as possible implications and difficulties of its implementation. The main argument is that the dialogic principle represents an aspect directly related to the procedure's structure, whose real consequences still must be defined. However, this may impact the fulfillment of the victim's expectations. In any case, it seems that the greatest difficulties arise from the diversity of goals pursued by crimes prosecution in this context and the tensions between them, due to the criminal, restorative and transitional nature of the Special Jurisdiction for Peace.

Keywords: criminal procedure, transitional justice, Special Jurisdiction for Peace, dialogic principle.

\section{Introducción}

La Jurisdicción Especial para la Paz (JEP), como mecanismo de justicia transicional con carácter judicial, parte del Sistema Integral de Verdad Justicia Reparación y No Repetición (SIVJRNR) ${ }^{[1]}$ diseñado en el Acuerdo de Paz con las FARC-EP, ha sido estructurada a partir de una doble función. Por un lado, se encuentra el juzgamiento de los crímenes cometidos con anterioridad al 1 de diciembre de 2016, "por causa, con ocasión o en relación directa o indirecta con el conflicto armado, por quienes participaron en el mismo" ${ }^{[2]}$, y que pueden ser considerados graves violaciones a los derechos humanos o graves infracciones al derecho internacional humanitario $(\mathrm{DIH})^{[3]}$. Por otro lado, y de forma paralela, también está la concesión de beneficios conforme lo establece la Ley 1820 de 2016 o Ley de Amnistía (LA) ${ }^{[4]}$, así como el control que debe ejercer la JEP sobre el cumplimiento de los requisitos emanados de los beneficios concedidos ${ }^{[5]}$. En estos casos también se trata de conductas punibles cometidas "por causa, con ocasión o en relación directa o

Notas de autor

\footnotetext{
${ }^{a}$ Autor de correspondencia. Correo electrónico: gcote@javeriana.edu.co
} 
indirecta con el conflicto armado" ${ }^{[6]}$, aunque no de graves violaciones a los derechos humanos ni de graves infracciones al DIH ${ }^{[7]}$. Pues bien, el proceso con reconocimiento de responsabilidad, regulado en la Ley 1922 de 2018 o Ley de Procedimiento de la JEP (LP-JEP) constituye una de las modalidades que puede tener lugar en ejercicio de la función de juzgamiento de esta jurisdicción especial y transitoria.

Este proceso supone que el compareciente acepte su responsabilidad en los crímenes que le sean puestos de presente por la Sala de Reconocimiento de Verdad, de Responsabilidad y de Determinación de los Hechos y Conductas (en adelante, Sala de Reconocimiento) ${ }^{[8]}$, la cual hasta el momento ha abierto siete casos. [9] También exige el compromiso del compareciente de contribuir a la satisfacción de los derechos de las víctimas a la verdad y la reparación. ${ }^{[10]}$ Como resultado, la Sección de Primera Instancia para casos con Reconocimiento del Tribunal para la Paz (en adelante, Sección de Primera Instancia) debe imponer al compareciente una sanción, denominada sanción propia, ${ }^{[11]}$ que no implica privación de la libertad, pero está conformada por un componente de restricción de derechos y otro reparador. ${ }^{[12]}$ Pero, además, el proceso con reconocimiento de responsabilidad en la JEP debe tener, según lo disponen los art. 1 (b) y 27 de la LPJEP, carácter dialógico; de hecho, el art. 1 (b) trata este aspecto como un principio. Sin embargo, el principio dialógico no aparece claramente definido en las normas procesales ni sus consecuencias sobre la estructura o dinámica procesal son evidentes.

El presente artículo se propone, por consiguiente, determinar qué significado puede tener el principio dialógico en el proceso con reconocimiento de responsabilidad en la JEP, así como explorar posibles implicaciones y dificultades de su concreción. Para esto, el artículo se ha dividido en cuatro partes. En la primera parte se discutirá sobre los objetivos que inspiran los procesos orientados al juzgamiento de crímenes graves en la JEP, para establecer un marco de referencia que permita reflexionar, en concreto, sobre el proceso con reconocimiento de responsabilidad. ${ }^{[13]}$ En la segunda parte se reseñarán las normas de la LP-JEP que regulan el proceso con reconocimiento de responsabilidad y se identificarán vacíos y ambigüedades, con el fin de encontrar posibles implicaciones del principio dialógico. En la tercera parte se hará alusión a algunos aspectos procesales que la práctica de la JEP ha decantado hasta el momento, tratando de establecer cómo se ha manifestado en ella dicho principio. Finalmente, a partir de las particularidades de la JEP, se platearán algunas reflexiones sobre posibles retos a los que se enfrenta la persecución penal en este proceso de transición.

$\mathrm{El}$ argumento central de este artículo es que el principio dialógico constituye un aspecto directamente relacionado con la estructura y el alcance del proceso con reconocimiento de responsabilidad, cuyas implicaciones reales aún están por definirse. Sin embargo, la manera como esto ocurra tendrá consecuencias sobre la medida en que se responderá a las expectativas de las víctimas. Dicho principio podría concretarse entonces de dos maneras. O bien dando espacios de participación, en los que los sujetos procesales e intervinientes podrán intentar persuadir a los magistrados de la JEP. De esta manera las víctimas harían las veces, sobre todo, de fuente de información. O se podría concretar mediante espacios de interacción directa entre comparecientes y víctimas, buscando la construcción de acuerdos sobre la verdad y la sanción propia. En todo caso, probablemente este aspecto se definirá dependiendo de la manera como se resuelvan las tensiones que surgen de los distintos objetivos que se persiguen con este proceso, en cuanto proceso penal, orientado por el paradigma de la justicia restaurativa, en un contexto transicional.

Antes de comenzar se deben hacer algunas precisiones metodológicas. El punto de partida de las consideraciones que a continuación se exponen es la Ley 1922 de 2018. Sin embargo, esta ley, por sí sola, no permite observar las complejidades del proceso que aquí se quiere analizar. De hecho, una de las mayores dificultades en la elaboración de este trabajo ha sido encontrar información que refleje la dinámica del proceso con reconocimiento de responsabilidad. Por esta razón, además de tener en cuenta la legislación y jurisprudencia pertinentes, se ha acudido a dos estrategias adicionales, con el fin de lograr una idea más cercana a la realidad de las actuaciones de esta jurisdicción. En primer lugar, se presentaron varios derechos de petición tanto a diferentes órganos de la JEP ${ }^{[14]}$, como a algunas entidades llamadas a promover la participación de 
las víctimas en este contexto ${ }^{[15]}$, y, en segundo lugar, se llevó a cabo un ejercicio de observación de varias de las audiencias que hasta el momento se han hecho públicas en la red ${ }^{[16]}$. La imagen que aquí se trasmite sobre los procesos con reconocimiento de responsabilidad constituye, de todas maneras, una "foto" - que no deja de ser parcial—, de un proceso bastante dinámico y todavía en construcción. Con esta imagen "congelada en el tiempo" se espera, de todas maneras, proporcionar insumos para reflexionar sobre los desafíos del derecho penal en contextos de justicia transicional.

\section{Objetivos del proceso con reconocimiento de responsabilidad en la JEP: tensión entre la dimensión penal, restaurativa y transicional}

Con el fin de analizar el carácter dialógico del proceso con reconocimiento de responsabilidad en la JEP es necesario preguntarse por los objetivos que se persiguen con dicho proceso, en la medida en que el proceso judicial es en esencia un medio para algo ${ }^{[17]}$ y la estructura y metodologías empleadas en él deben ser consecuentes con su finalidad. En este sentido, parece razonable suponer que los objetivos de los procesos que se adelantan en la JEP - y como tal, del proceso con reconocimiento de responsabilidad- están determinados, o al menos deberían estarlo, por los objetivos más generales de esa jurisdicción especial y del SIVJRNR, del cual hace parte. A continuación, se explorará cuáles son dichos objetivos, con el fin de delimitar un marco de referencia que permita reflexionar sobre la conveniencia de la estructura del proceso con reconocimiento de responsabilidad.

Los objetivos de este sistema como de la JEP fueron definidos en el Acuerdo de Paz firmado por el Gobierno colombiano y las FARC-EP. Según el Acuerdo de Paz, el SIVJRNR pretende lograr "un máximo de justicia y de rendición de cuentas sobre las violaciones a los derechos humanos e infracciones al DIH ocurridas a lo largo del conflicto" ${ }^{[18]}$. Por consiguiente, entre los objetivos de la JEP, como componente de justicia de dicho sistema, se encuentran la satisfacción del "derecho de las víctimas a la justicia, ofrecer verdad a la sociedad colombiana [...] contribuir al logro de una paz estable y duradera, y adoptar decisiones que otorguen plena seguridad jurídica a quienes participaron de manera directa o indirecta en el conflicto armado interno". ${ }^{\text {[19] }}$ Para esto, en todas las actuaciones, según se dispuso en el Acuerdo, se deben "tomar en cuenta como ejes centrales los derechos de las víctimas" ${ }^{[20]}$, de ahí que se haya establecido la noción de justicia restaurativa [21] como uno de los paradigmas orientadores de la JEP. Este tipo de justicia busca, según el Acuerdo de Paz, la "restauración del daño causado y la reparación de las víctimas afectadas por el conflicto, especialmente para acabar la situación de exclusión social que les haya provocado la victimización” "22] , así como atender prioritariamente sus necesidades ${ }^{[23]}$.

Objetivos como ofrecer verdad a la sociedad colombiana y acabar situaciones de exclusión social permiten preguntarse si los procesos que se deben surtir en la JEP son realmente procesos penales ${ }^{[24]}$ en el sentido más común, es decir como sucesión de actos mediante los cuales se busca determinar si una norma jurídico-penal ha sido quebrantada y establecer, como consecuencia, la responsabilidad individual, con miras a formular un reproche jurídico manifestado en la imposición de una pena ${ }^{[25]}$. Sin embargo, no se puede desconocer que el punto de partida del Acuerdo de Paz, al definir tanto el SIVJRNR como la JEP, es la comisión de crímenes y la necesidad, como parte del derecho a la justicia de las víctimas, de sancionarlos, sin "intercambiar impunidades" ${ }^{[26]}$, y que incluso las partes que suscribieron el Acuerdo se han propuesto, al diseñar la JEP, "avanzar en la lucha contra la impunidad" [27] (cursivas añadidas), en casos en los que no es posible otorgar amnistías o renunciar a la persecución penal ${ }^{[28]}$. En consecuencia, los procesos que tienen lugar en la JEP se deben considerar procesos de carácter penal, incluso el proceso con reconocimiento de responsabilidad, y sus objetivos se deben evaluar, en primer lugar, desde esta perspectiva. ${ }^{\text {[29] }}$ 
El proceso penal se puede concebir como respuesta a un conflicto jurídico-penal, que surge al ponerse en tela de juicio la validez del derecho vigente, entendido este como conjunto de parámetros normativos que indican el comportamiento debido en sociedad para evitar la lesión de bienes jurídicos ${ }^{[30]}$. En este sentido, como lo explica Kindhäuser, solo la sospecha del quebrantamiento de la norma (de comportamiento) jurídico-penal es conflictiva y exige, en consecuencia, una reacción estatal ${ }^{[31]}$. El proceso penal constituye esta reacción y con él se busca confirmar o desvirtuar dicha sospecha ${ }^{[32]}$. De confirmarse el quebrantamiento de la norma, el proceso da lugar a la imposición y consecuente ejecución de la pena, con el fin de reafirmar la vigencia de la norma quebrantada y reestablecer la paz jurídica ${ }^{[33]}$. El proceso, así como la imposición y ejecución de la sanción forman entonces un continuum ${ }^{[34]}$, cuya función es materializar los fines del derecho penal [35]. Sin embargo, el cumplimiento de esta función está supeditado, en todo caso, a la consecución de tres objetivos procesales más concretos: la determinación de la verdad, la realización de la justicia — material y procedimental - y la consecución de estabilidad jurídica. ${ }^{[36]}$

Determinar lo que realmente sucedió ante la sospecha del quebrantamiento de la norma es una condición necesaria para hacer posible la subsunción de la situación de hecho analizada en el precepto contenido en la norma penal ${ }^{[37]}$. No obstante, la aplicación del derecho penal material con el fin de reafirmar la vigencia del ordenamiento jurídico no puede ser resultado de una nueva vulneración de este último. De ahí que no solo se requiera una decisión justa desde el punto de vista material que corresponda a la verdad y en la que se aplique correctamente el derecho sustantivo, sino que también se necesite una decisión producto de un proceder justo, es decir, respetuoso de las garantías del debido proceso ${ }^{[38]}$. La decisión tomada en el contexto de un proceso orientado a la consecución de la verdad y en cumplimiento de garantías fundamentales debe gozar, además, de estabilidad, para que sus efectos sean reales ${ }^{[39]}$. Los procesos de la JEP que buscan juzgar crímenes graves, en cuanto procesos penales, no deben perder de vista estos tres objetivos ni la función que con miras al derecho penal en general están llamados a cumplir.

Esta visión del proceso penal adquiere, sin embargo, una dimensión diferente cuando se toma en cuenta la perspectiva de la víctima ${ }^{[40]}$, como se hace en el Acuerdo de Paz y, en general, desde la noción de justicia transicional ${ }^{[41]}$. Al incluir a la víctima, el conflicto que se genera ante la posible comisión de un crimen puede ser redefinido, ya no solamente como conflicto entre el eventual sujeto infractor y el derecho vigente, sino entre el sujeto infractor y la persona afectada por su conducta, ambos como sujetos de derechos y obligaciones ${ }^{[42]}$. En este contexto la búsqueda de la verdad adquiere otra connotación, ya que esta no solo constituye una condición de la correcta aplicación del derecho sustantivo, sino también una forma de satisfacción para la víctima ${ }^{[43]}$. La noción de justicia también adquiere así una dimensión adicional, puesto que no solo es relevante la aplicación justa del derecho penal material — si es del caso imponiendo la pena que legalmente corresponda - , como resultado de un proceso justo, sino también el restablecimiento —en lo posible- de los derechos conculcados, lo que da lugar a la noción de reparación ${ }^{[44]}$ como objetivo del proceso penal y permite hablar en este contexto de justicia restaurativa ${ }^{[45]}$.

Esta perspectiva ha permeado el proceso penal ordinario colombiano, generando espacios de participación de las víctimas y abriendo las puertas a figuras procesales como la conciliación o la mediación ${ }^{[46]}$. Sin embargo, en contextos de justicia transicional, en los que se busca juzgar violaciones masivas de derechos humanos e infracciones al DIH - como ocurre en la JEP —, para que este tipo de hechos queden realmente en el pasado y no se repitan, estos objetivos también se expanden ${ }^{[47]}$. Es decir, en contextos de justicia transicional no solamente se está ante la necesidad de lograr los objetivos "tradicionales" del proceso penal; la satisfacción de los derechos de las víctimas también juega aquí un papel fundamental, pero con un alcance mayor de los que estos mismos derechos tienen en el proceso penal ordinario. Esta circunstancia permite explorar diferentes metodologías, por ejemplo, para llegar a la verdad, para determinar los daños a reparar e incluso, como sucede 
en la JEP, para determinar la sanción, lo cual incide —o debería incidir - en el tipo de proceso penal y su estructura.

En contextos de justicia transicional tanto el proceso como sus resultados esperados revisten, en consecuencia, ciertas particularidades. El proceso en sí mismo adquiere en estas situaciones especial relevancia, probablemente como resultado de la reducción en la drasticidad de la reacción penal, lo que desplaza el énfasis de la sanción a las actuaciones procesales ${ }^{[48]}$. Al ser un escenario público en el que se reconstruyen hechos graves de violencia masiva y se (re)encuentran sus protagonistas, el proceso - así como las actuaciones que en él se realizan - adquiere un fuerte poder expresivo que puede constituir incluso una importante oportunidad de catarsis ${ }^{[49]}$. El proceso se convierte así en un escenario de "condena" pública de los hechos discutidos ${ }^{[50]}$, al tiempo que se constituye en un escenario de reconocimiento de las víctimas, de su dolor, de su historia y de sus derechos ${ }^{[51]}$; este escenario permite también individualizar los hechos, para mostrar que personas específicas son responsables, y no solo grupos étnicos, religiosos o políticos ${ }^{[52]}$. Así, se busca terminar una especie de .cultura de impunidad. que surge cuando en una sociedad se generaliza la idea de que la comisión de hechos especialmente graves no desata ninguna reacción estatal negativa, lo cual debilita los parámetros morales que subyacen a las prohibiciones penales de este tipo conductas ${ }^{[53]}$. En últimas, de esta manera se quiere fortalecer la idea del Estado de Derecho ${ }^{[54]}$.

Con relación a los resultados, el proceso penal en contextos de justicia transicional se encuentra ante la necesidad de responder a una doble perspectiva: colectiva - o macro- e individual -o micro-. Desde el punto de vista colectivo o macro, teniendo en cuenta que los mecanismos de justicia transicional pretenden facilitar la construcción de paz y dejar atrás situaciones de violencia masiva, la verdad que se pretende surja del proceso es una verdad que dé cuenta de las causas de la violencia y de su dinámica ${ }^{[55]}$. Se trata entonces de una verdad con pretensión histórica que debe aludir a los procesos políticos y sociales que fomentaron la violencia ${ }^{[56]}$. Con esto se busca entender lo que sucedió y dejar un registro histórico - con autoridad y estabilidad jurídica- que sirva de lección para el presente y el futuro ${ }^{[57]}$. La reparación y la justicia deben, en consecuencia, responder a esta verdad, nuevamente, con el fin último de la no repetición. En términos de reparación, se pretenden tomar medidas que de alguna manera impacten, precisamente, en los procesos sociales y políticos que generaron la situación de violencia ${ }^{[58]}$, mientras que, en términos de justicia, se busca sancionar a quienes incidieron en el diseño o implementación de las políticas que implicaron violaciones masivas de derechos humanos ${ }^{[59]}$. Como resultado, al hablar de víctima(s) desde esta perspectiva, también se hace referencia de manera impersonal a una noción colectiva de víctima, entendiendo como tal un grupo, una comunidad, un partido político, etc.

Desde el punto de vista individual o micro, se está ante la necesidad de dar, en alguna medida, respuestas concretas a las víctimas directas o indirectas de las violaciones de derechos humanos o infracciones al DIH, cuya repetición se busca evitar. La verdad, en este sentido, es la verdad del hecho victimizante específico, de las circunstancias que lo motivaron y de la forma como se cometió. La reparación atiende aquí a los daños concretos que hayan sufrido las víctimas directas o indirectas, mientras que la justicia se refiere a la sanción de los responsables, no de las políticas o actuaciones de los grupos involucrados en la situación de violencia masiva que se quiere dejar atrás, sino de los hechos delictivos concretos que afectaron a la víctima individualizada, es decir quienes materialmente participaron en su perpetración. Es esta perspectiva individual la que permite conectar la noción de justicia transicional con la de justicia restaurativa, haciendo del proceso penal en contextos transicionales una construcción aún más compleja.

En términos generales, la noción de justicia restaurativa surge como alternativa distinta a la respuesta punitiva que se da ante el crimen ${ }^{[60]}$. Desde el paradigma restaurativo se busca reconstruir las relaciones sociales que se ven afectadas con el delito, tomando en serio la perspectiva de la víctima, lo cual implica hacer énfasis en la reparación del daño causado antes que en la imposición de una pena ${ }^{[61]}$. Sin embargo, el 
enfoque restaurativo supone articular mecanismos de justicia de manera descentralizada, que operen a nivel local en la comunidad que se vio afectada por la comisión del crimen ${ }^{[62]}$. El carácter local busca facilitar la interacción entre las personas responsables y las afectadas, para encontrar soluciones prontas a través del diálogo ${ }^{[63]}$. El objetivo es construir la verdad mediante esta interacción, lo que permite hablar en este contexto preponderantemente de verdad dialógica ${ }^{[64]}$ y no tanto de verdad forense ${ }^{[65]}$ o "simplemente" narrativa ${ }^{[66]}$ . Víctima y victimario construyen entonces consensualmente, incluso con la participación de la comunidad, la verdad sobre lo ocurrido y determinan, también de esta manera, las consecuencias (reparadoras) que se deben asumir ${ }^{[67]}$. Por consiguiente, pensar el proceso penal desde este paradigma tiene consecuencias tanto en su estructura como en las metodologías que en él se implementan, dado que en dicho caso el proceso debe permitir espacios de esta naturaleza. Sin embargo, aceptar el enfoque restaurativo en un proceso penal que constituye a la vez un mecanismo de justicia transicional se enfrenta al gran reto de tener que generar dinámicas de este estilo entre sus intervinientes, al tiempo que debe responder a la perspectiva colectiva o macro que se señaló líneas arriba. Ante esta tensión es razonable pensar que la búsqueda de un punto intermedio necesariamente implica ceder en la consecución de los objetivos (propios) de ambas perspectivas.

La JEP se encuentra precisamente ante esta encrucijada y los procesos que en ella se surten - y se surtirán - probablemente deberán conciliar la búsqueda de diversos tipos de objetivos. Por esto, con relación a la JEP se habla de persecución penal y, en consecuencia, las personas responsables de los crímenes investigados se deben individualizar, ${ }^{[68]}$ aunque dicha investigación se debe guiar por las nociones de macrocriminalidad ${ }^{\text {[69] }}$ y macrovictimización, ${ }^{[70]}$ lo cual supone investigaciones complejas en las que también se deben identificar, por un lado, las estructuras y el funcionamiento de las organizaciones criminales, así como sus redes de apoyo y los patrones delictivos que caracterizaron sus actuaciones, como, por otro lado, grupos de víctimas con características comunes que hayan padecido el mismo tipo de violencia. ${ }^{[71]}$ En este mismo sentido, se prevén como parte de la sanción propia medidas reparadoras con alcance claramente colectivo ${ }^{[72]}$. Adicionalmente, al mismo tiempo se habla de justicia restaurativa, pero haciendo alusión tanto a la reparación de las víctimas como a la terminación de situaciones de exclusión social ${ }^{[73]}$, erigiendo el principio dialógico como uno de los principios rectores de la jurisdicción ${ }^{[74]}$.

Siendo la JEP un mecanismo judicial con el cual se busca sancionar a personas penalmente responsables de la comisión de crímenes graves, estos procesos deben atender entonces a los objetivos generales del proceso penal. Sin embargo, el paradigma restaurativo, en el que se fundamenta el principio dialógico, debe orientar las actuaciones procesales que se realicen en este contexto, sin perder de vista que, debido a que la JEP también es un mecanismo de justicia transicional, se espera que los procesos que aquí se adelanten contribuyan a la verdad, a la justicia y a la reparación desde una perspectiva colectiva. La pregunta es si, o qué tanto, el diseño procesal realizado en la LP-JEP, en particular para casos con reconocimiento de responsabilidad, responde o no a esta complejidad.

\section{Estructura normativa del proceso con reconocimiento de responsabilidad en la JEP: vacíos e interrogantes en la Ley 1922 de 2018}

El proceso penal en la JEP, a través del cual se juzgan conductas no amnistiables, se puede desarrollar por medio de dos alternativas ${ }^{[75]}$. El proceso puede darse sobre la base del reconocimiento de responsabilidad que realiza el compareciente ${ }^{[76]}$, en cuyo caso no hay juicio ${ }^{[77]}$, o puede partir de la negativa del compareciente a aceptar su responsabilidad en los hechos, lo que da lugar a la posibilidad de presentar una acusación formal y a un juicio con ejercicio pleno del derecho de defensa ${ }^{[78]}$. Cada una de estas dos modalidades de proceso 
se encuentra regulada en la LP-JEP y su existencia ha permitido que en este contexto se plantee la dicotomía entre el principio dialógico y el principio adversarial.

Entre los principios rectores de la JEP, la Ley de Procedimiento hace referencia en el art. 1 (b) al principio dialógico y lo contrapone, precisamente, al principio adversarial. Sin embargo, esta disposición no define ninguno de estos dos principios. El primer inciso del art. 1 (b) LP-JEP simplemente dispone: "[e]l procedimiento en casos de reconocimiento de la verdad tendrá un carácter dialógico o deliberativo, con participación de las víctimas y de los comparecientes a la JEP” (cursivas añadidas), mientras el tercer inciso afirma: "[s]e aplicará de preferencia el principio dialógico sobre el adversarial", y aclara que en todo caso se deberá respetar el debido proceso y el derecho de defensa. ${ }^{[79]}$ De estas dos partes del art. 1 (b) se desprende que el carácter dialógico se predica del proceso con reconocimiento de responsabilidad y no del tipo de proceso en el que debe haber juicio. Esto genera la pregunta sobre el sentido y alcance de este principio, sobre todo si se tiene en cuenta que "dialógico" se asimila en esta norma a "deliberativo" y que "deliberar", en su sentido literal, quiere decir "[c] onsiderar atenta y detenidamente el pro y el contra de los motivos de una decisión, antes de adoptarla, y la razón o sinrazón de los votos antes de emitirlos" ${ }^{[80]}$. Es decir, según una interpretación gramatical del primer inciso del art. 1 (b) LP-JEP, en los procesos con reconocimiento de responsabilidad tanto las víctimas como los comparecientes deben participar en la consideración de los pros y contras de las decisiones que en ellos se tomen.

Pero ¿cómo se debe dar esta participación?, ¿en qué momentos o etapas procesales se debe aplicar al principio dialógico?, ¿el carácter dialógico o deliberativo del proceso se debe manifestar en cualquier tipo de decisión que se tome en su desarrollo? Son interrogantes que genera el art. 1 (b) LP-JEP. Con el fin de indagar posibles respuestas y de advertir sobre posibles inconvenientes, es necesario dar una mirada a la estructura de este tipo de proceso, la cual, vale decirlo, fue definida en la LP-JEP de manera bastante general.

El proceso penal con reconocimiento de responsabilidad en la JEP se encuentra regulado en los art. 27 a 33 LP-JEP. Al respecto, es importante resaltar, en primer lugar, que el art. 27 reitera su carácter dialógico y concreta un poco lo establecido en el art. 1 (b) LP-JEP. El art. 27 alude específicamente a la construcción de la verdad, como forma de justicia restaurativa. En este sentido, dicha norma afirma que las salas y secciones —estas últimas, del Tribunal para la Paz-podrán adoptar, cuando corresponda, "las medidas que estimen oportunas e idóneas para promover la construcción dialógica de la verdad entre los sujetos procesales e intervinientes" (cursivas añadidas). Además, en el parágrafo, el mismo art. 27 hace alusión al proyecto de sanciones que debe incluir la Sala de Reconocimiento en las resoluciones de conclusiones que se entregarán a la Sección de Primera Instancia. Estas sanciones deben tener contenido reparador ${ }^{[81]}$ y, conforme lo dispone el parágrafo del art. 27 LP-JEP, podrán ser definidas con participación de las víctimas ${ }^{[82]}$. Es decir, el art. 27 concreta lo dispuesto en el art. 1 (b) LP-JEP, al precisar que el carácter dialógico o deliberativo puede manifestarse en la determinación de dos aspectos fundamentales en el juzgamiento de crímenes: la determinación de los presupuestos de la responsabilidad — construcción de la verdad-y la determinación de sus consecuencias - propuesta de sanción propia-.

Con el objetivo de definir estos dos aspectos, las salas y secciones deben promover, según esta misma norma, "la construcción de acuerdos [...] en todas las fases del procedimiento" [83] (cursivas añadidas), mediante la participación deliberativa tanto de víctimas como de comparecientes. Sin embargo, expresiones como "medidas [...] oportunas e idóneas" o "construcción de acuerdos", de las que depende la materialización del principio dialógico, en los términos definidos en el art. 27 LP-JEP, siguen siendo vagas y no permiten dilucidar, en concreto, cómo se manifestará dicho principio en este tipo de procesos. Las dudas sobre la forma como se debe materializar el principio dialógico se acrecientan cuando se miran, con un poco más de detenimiento, las dos grandes etapas que componen este proceso. La primera etapa tiene lugar ante la Sala de Reconocimiento, mientras que la segunda se surte ante la Sección de Primera Instancia del Tribunal para la Paz. 
Los procesos penales de la JEP, mediante los cuales se busca juzgar conductas punibles no amnistiables, inician su curso ante la Sala de Reconocimiento, la cual debe recaudar información a través de diferentes fuentes, con el fin de estructurar los casos sobre los que interrogará a los comparecientes. Para esto, la Sala puede utilizar informes, tal como se previó desde el Acuerdo de Paz, ${ }^{[84]}$ presentados por instituciones del Estado que hayan realizado investigaciones por hechos acaecidos con ocasión del conflicto armado o impuesto sanciones por esta misma razón - o por organizaciones de víctimas y de derechos humanos colombianas ${ }^{[85]}$. Estos informes deben ser puestos a disposición de las personas mencionadas en ellos como (posibles) responsables ${ }^{[86]}$. Una vez dichas personas han conocido estos informes, pueden ser llamadas por la Sala de Reconocimiento a rendir una versión voluntaria ${ }^{[87]}$, diligencia en la que el compareciente tendrá la oportunidad de aceptar, con valor de confesión ${ }^{[88]}$, la autoría o participación ${ }^{[89]}$ en los crímenes que allí le sean puestos de presente. Sin embargo, el objetivo de las versiones voluntarias, al menos de acuerdo con el art. 27 A LP-JEP, pareciera ser "el acopio de información para contribuir a la búsqueda de la verdad” y no, podría agregarse entonces, la aceptación de responsabilidad.

La Sala de Reconocimiento debe contrastar los informes recibidos con el "acervo probatorio". Esta labor está prevista en el art. 27 B LP-JEP ${ }^{[90]}$; sin embargo, esta norma genera varios interrogantes relacionados con la estructura del proceso. En primer lugar, no es del todo claro a cuál acervo probatorio se refiere este artículo. Es decir, ¿debe la Sala, al recibir los informes, practicar otro tipo de pruebas? En caso afirmativo ¿cuáles?, ¿podría, por ejemplo, citar personas distintas a los comparecientes, para que rindan alguna clase de testimonio o declaración u ordenar inspecciones judiciales o peritajes? Al respecto la LP-JEP no es clara, aunque se debe mencionar que las salas de la JEP y las secciones del Tribunal para la Paz pueden, en general, ordenar de oficio la práctica de pruebas ${ }^{[91]}$. En segundo lugar, la redacción del art. $27 \mathrm{~B}$ genera preguntas sobre el momento en el que debe darse la versión voluntaria y la aceptación de responsabilidad.

Esta norma se refiere, al parecer, como un primer paso, a la confrontación de los informes con el "acervo probatorio" y, con posterioridad, aparentemente, como un segundo momento a las versiones voluntarias, las cuales, de todas maneras, también deben ser contrastadas con el resto de información disponible ${ }^{\text {[92] }}$. El problema radica en que según el art. $27 \mathrm{~B}$, "después de haber tenido en cuenta las versiones voluntarias de que trata el artículo anterior", la Sala de Reconocimiento debe "ponerlos a disposición de los presuntos responsables para que tomen la decisión de comparecer o no a efectuar el aporte de verdad y reconocimiento, o a defenderse de las imputaciones formuladas" [93] (cursivas añadidas). Parece lógico suponer que, al decir ponerlos, el art. $27 \mathrm{~B}$ alude a los informes, aunque en este punto, debido a su mala redacción, la norma es ambigua. En todo caso, si se interpretara literalmente esta disposición, la Sala debería recibir los informes, realizar las versiones, y después poner los informes a disposición de los comparecientes para que decidan si hacen o no el aporte a la verdad y el respectivo reconocimiento de responsabilidad. Así entendido el art. $27 \mathrm{~B}$, resultaría contradictorio con lo dicho en el párrafo anterior, ya que de acuerdo con el art $27 \mathrm{~A}$, como es lógico, las versiones voluntarias se deben realizar una vez los comparecientes han conocido los informes. Pero más allá de esto, la redacción del art. $27 \mathrm{~B}$ permite preguntar si finalmente el reconocimiento de responsabilidad debe tener lugar o no en la versión voluntaria o si más bien se debe dar en un momento posterior, con mayor razón si se tiene en cuenta que la LP-JEP, en el art. $27 \mathrm{C}$, habla de una audiencia pública de reconocimiento de verdad y responsabilidad.

$\mathrm{Al}$ leerse en conjunto los art. 27 A, 27 B y 27 C de la LP-JEP, surgen entonces varios interrogantes. ¿Cuál es el momento procesal en el que puede tener lugar el reconocimiento de responsabilidad jurídicamente vinculante, es decir, el reconocimiento de los hechos que determina la base fáctica para la imputación de responsabilidad penal: la versión voluntaria o la audiencia de reconocimiento de verdad y responsabilidad? De ser la versión voluntaria, por tener valor de confesión el reconocimiento que allí se realizaría, ¿cuál sería entonces el valor jurídico de la audiencia pública mencionada en el art. 27 C?, ¿esta diligencia sería solo una especie de ratificación pública del reconocimiento de responsabilidad hecho con anterioridad?, ¿qué sucedería entonces si en esta audiencia el alcance de la manifestación de voluntad del compareciente no 
coincide con el reconocimiento hecho en la versión voluntaria? En caso de aceptarse que el reconocimiento de responsabilidad jurídicamente válido es el que tiene lugar durante la audiencia del art. $27 \mathrm{C}$, ¿cuál sería entonces el efecto de la confesión mencionada en el art. $27 \mathrm{~A}$ ?

La respuesta a estos interrogantes se hace aún más compleja si se tiene en cuenta que el art. 27 A LP-JEP no prevé la participación de las víctimas en las versiones voluntarias, mientras que el art. $27 \mathrm{C}$ solo habla de participación de "organizaciones de víctimas invitadas" [94] (cursivas añadidas) por la Sala de Reconocimiento, e incluso autoriza a llevar a cabo el reconocimiento de responsabilidad por escrito. El problema de estos vacíos en el diseño normativo del proceso, para lo que constituye el punto de interés de este artículo, es que no se entiende entonces cómo se concreta en medio de estas diligencias el carácter dialógico que se supone inspira el juzgamiento de crímenes no amnistiables en la JEP. Aunque en el marco del proceso 003 la Sala de Reconocimiento aceptó, bajo ciertas condiciones, la presencia de abogados de víctimas en las versiones y la posibilidad de que uno de ellos, previamente seleccionado, formule preguntas ${ }^{[95]}$, las dudas respecto a la materialización del principio dialógico persisten, dado que incluso esta posibilidad parece lejana a la idea de deliberación y construcción de acuerdos.

Se debe tener en cuenta, en todo caso, lo dispuesto en el art. $27 \mathrm{D}$ sobre participación de las víctimas en el procedimiento ante la Sala de Reconocimiento. Una interpretación sistemática del art. $27 \mathrm{C}$ con el art. $27 \mathrm{D}$ debería llevar a la conclusión de que a la audiencia de reconocimiento no solo podrían asistir las organizaciones de víctimas invitadas, sino también las víctimas que tangan interés directo o legítimo ${ }^{[96]}$, lo que podría interpretarse como víctimas directas o indirectas de los crímenes a juzgar, sin que su participación tenga que estar mediada por ninguna organización. Esto se desprende del encabezado del art. $27 \mathrm{D}$, en donde se hace referencia, precisamente, a los derechos de las víctimas "con interés directo y legítimo". La pregunta es, de todas maneras, ¿qué podrían hacer las víctimas en esta diligencia? El art. $27 \mathrm{D}$ menciona la presentación de observaciones sobre varios temas, pero en ninguno de sus numerales pareciera referirse a la intervención directa en las audiencias. Así, por ejemplo, el numeral 4 prevé la presentación de observaciones sobre las versiones voluntarias, pero con posterioridad a su realización ${ }^{[97]}$, mientras que el numeral 5 habla de la presentación de observaciones sobre las resoluciones de conclusiones, pero por escrito y "dentro de los 15 días hábiles posteriores" a la audiencia pública de reconocimiento ${ }^{[98]}$. Aunque se debe tener en cuenta que, según el art. 15 (g) de la Ley 1957 de 2019 (Ley Estatutaria de la JEP), las víctimas tienen derecho a "[s]er informadas a tiempo de cuándo se llevarán a cabo las distintas audiencias del proceso, y a intervenir en ellas" (cursivas añadidas), la forma y objetivo de su posible intervención en la audiencia de reconocimiento son inciertos. Nuevamente, surge el interrogante sobre el alcance real del carácter dialógico del proceso.

Después de la contribución a la verdad y del reconocimiento de responsabilidad que hace el compareciente ante la Sala de Reconocimiento, el proceso debe seguir su curso ante el Tribunal para la Paz, concretamente, ante la Sección de Primera Instancia para casos con Reconocimiento ${ }^{[99]}$. El traslado del proceso de la Sala a la Sección ocurre mediante el envío de la resolución de conclusiones que la Sala profiera en el caso respectivo. Sin embargo, la LP-JEP no precisa el término dentro del cual se debe proferir esta resolución ni aclara cuál es en concreto el rol de las víctimas en este paso. La única referencia que en estas normas se hace a la resolución de conclusiones aparece en el numeral 5 del art. $27 \mathrm{D}$, ya mencionado, para decir que las víctimas pueden, dentro de los quince días posteriores a la audiencia pública de reconocimiento, presentar observaciones finales escritas sobre todos los "aspectos concernientes a la Resolución de Conclusiones". Es claro entonces que la resolución de conclusiones se debe proferir después del reconocimiento de responsabilidad, pero la norma es ambigua, puesto que no concreta el objeto de las observaciones; es decir, ¿las observaciones de las víctimas se deben presentar después del reconocimiento de responsabilidad para que la Sala las tenga en cuenta en el momento de proferir la resolución de conclusiones, o se trata de observaciones sobre la resolución una vez esta ha sido proferida? De estas dos alternativas la primera parece más razonable, puesto que, si el sentido de la norma fuera la segunda posibilidad, la Sala estaría obligada a proferir la resolución de conclusiones en 
algún momento dentro de los quince días que tienen las víctimas para presentar estas observaciones. Por esta razón, el orden parece ser el siguiente: reconocimiento de responsabilidad del compareciente, presentación de observaciones por parte de las víctimas dentro de los quince días siguientes y luego sí producción de la resolución de conclusiones, sin que para esto último se haya previsto algún plazo en la LP-JEP.

Es posible preguntar entonces qué sucede si las víctimas tienen reparos con relación a la resolución de conclusiones. Al respecto se debe advertir que, conforme al art. 12 LP-JEP, contra la resolución de conclusiones procede el recurso de reposición. Sin embargo, esta resolución no se menciona en el art. 13 LP-JEP entre las decisiones que dan lugar al recurso de apelación ${ }^{[100]}$. En consecuencia, pareciera que la intervención de las víctimas aquí se reduce a la posibilidad de presentar observaciones después del reconocimiento de responsabilidad y antes de la resolución de conclusiones y a la posibilidad de presentar recurso de reposición contra esta decisión. Si el principio dialógico se entiende como deliberación y construcción de acuerdos, la forma como está concebido este proceso, una vez más, parece inadecuada.

Cuando el proceso es recibido por la Sección de Primera Instancia y se ha producido el reparto conforme al art. 28 LP-JEP ${ }^{[101]}$, esta debe llevar a cabo la evaluación de correspondencia, en la que se deben examinar aspectos fácticos y de derecho relacionados con el reconocimiento de responsabilidad ${ }^{[102]}$. Esta evaluación se debe realizar dentro de los plazos previstos en el art. 29 LP-JEP ${ }^{[103]}$. Sin embargo, y a pesar de la importancia que parece tener esta etapa para el proceso, es difícil entender en qué consiste cada paso de los mencionados en dicha norma. Parece claro que una vez asumida la competencia por el magistrado ponente y notificado este hecho a los sujetos procesales e intervinientes, dicho magistrado tiene un plazo de 30 días (calendario) para realizar un estudio preliminar de la resolución de conclusiones y sus anexos ${ }^{[104]}$. Al respecto se debe presentar un informe a la Sección, para que dentro de noventa días se discuta "el enfoque" y se oriente "el estudio" - al margen de lo que se haya querido decir con esto-, al final de los cuales el magistrado ponente deberá presentar la ponencia respectiva ${ }^{[105]}$. Finalmente, la misma Sección fijará un término para estudiar la ponencia y tomar la decisión que considere procedente ${ }^{[106]}$.

Si la Sección de Primera Instancia determina la correspondencia al verificar los aspectos mencionados en el art. 29 LP-JEP ${ }^{[107]}$, se debe realizar una nueva audiencia pública "con el fin de verificar el cumplimiento de las condiciones de contribución a la verdad y a la forma de reparación en el marco del SIVJRNR" [108]. Esta audiencia se debe llevar a cabo dentro de los treinta días siguientes a la definición de correspondencia ${ }^{[109]}$. Después de esta audiencia, la Sección tendrá veinte días para dictar sentencia y fijar las condiciones y modalidades de la sanción ${ }^{[110]}$. En cambio, si la Sección establece la no correspondencia, debe citar a los sujetos procesales e intervinientes, y a la Sala de Reconocimiento, lo cual es peculiar, pues aquí los magistrados de este órgano son citados por el Tribunal a una especie de rendición de cuentas, para que den explicaciones sobre la resolución de conclusiones ${ }^{[111]}$. Si estas explicaciones no resultan convincentes, la Sección puede suspender la diligencia, máximo hasta por treinta días, en los que la Sección puede practicar pruebas de oficio, al final de los cuales se reanudará la audiencia, esperando que las insuficiencias hayan sido subsanadas y declarar, ahora sí, la correspondencia y continuar el curso del proceso para dictar sentencia ${ }^{[112]}$.

Es de resaltar que, en esta etapa, ante la Sección de Primera Instancia, ya deben estar definidos los cargos por los que responderá el compareciente, así como la propuesta de sanción propia. No parece entonces haberse previsto aquí ningún escenario de diálogo entre víctimas y comparecientes, más allá de la posibilidad de participar en el control que debe realizar la Sección sobre el grado de cumplimiento de las obligaciones impuestas o de intervenir ante la Sección en caso de que no se haya declarado la correspondencia. Aunque es posible imaginar que si la Sección, una vez escuchadas las explicaciones tanto de la Sala como de los sujetos procesales e intervinientes, suspende la audiencia, durante ese plazo podría tener lugar alguna clase de trabajo mancomunado entre estos actores, con el fin de "corregir" la resolución de conclusiones. Aquí podría manifestarse, aunque la LP-JEP no lo prevea expresamente, el carácter dialógico de este proceso. 


\section{Carácter dialógico o deliberativo del proceso con reconocimiento de responsabilidad en la JEP: un aspecto en construcción más allá de la Ley 1922 de 2018}

El proceso penal con reconocimiento de responsabilidad en la JEP ha tenido una dinámica bastante particular en la práctica. Esta dinámica permite observar la especial complejidad de este tipo de procesos y cómo la estructura procesal determinada normativamente, en términos bastante generales, no coincide exactamente con la forma como ellos se organizan en cada caso. Esto evidencia, por un lado, la precariedad de las normas procesales de la JEP, las cuales no siempre dan cuenta de la complejidad de los temas discutidos en ellos ni de sus objetivos ${ }^{[113]}$, pero, por otro lado, que tanto la ambigüedad como la vaguedad de la LP-JEP han dado lugar a un margen importante de decisión para que sus magistrados y magistradas "acomoden" los trámites a las exigencias que se presentan durante su desarrollo y así tratar de cumplir de una manera más adecuada dichos objetivos. Precisamente, entre estos objetivos se encuentra propender por la construcción de verdad y la reparación de las víctimas, a través de espacios dialógicos ${ }^{[114]}$.

El principio dialógico se ha empezado a manifestar entonces sobre todo en actuaciones procesales que, aunque trascienden lo dicho explícitamente en la LP-JEP, podrían entenderse como parte de las medidas "oportunas e idóneas" que, según el art. 27 LP-JEP, pueden tomar las salas y secciones "cuando corresponda", con el fin de "promover la construcción dialógica de la verdad". Esto, sin embargo, genera dilemas relacionados con el alcance real que tendrán estos procesos. Para explicar lo anterior es posible concentrar la atención en dos aspectos fundamentales. Se trata, en primer lugar, de la estructura procesal que la práctica de la JEP ha decantado hasta el momento y, en segundo lugar - aunque no menos importante-, del tipo de intervención que han tenido las víctimas en este contexto y la "interacción" tanto con comparecientes como con magistrados y magistradas.

\section{Estructura procesal decantada hasta el momento en la práctica de la JEP}

Visto desde el Acuerdo Final de Paz y las normas que se han expedido para su implementación, el proceso penal con reconocimiento de responsabilidad aparece como uno de los tipos de proceso que se surten en ejercicio de la función de juzgamiento de la JEP. Es decir, una es la dimensión de la JEP que opera cuando se trata de personas no condenadas - con o sin aceptación de responsabilidad- que no pueden acceder a beneficios penales y se deben juzgar y otra es la dimensión que opera ante personas condenadas o no, pero que acceden a beneficios penales y no se juzgan ${ }^{[115]}$. Estos dos escenarios, delimitados uno del otro en el plano normativo, pueden coincidir en la práctica, haciendo que frente al mismo compareciente operen paralelamente y se entrecrucen las dos dimensiones, involucrando, además, a las mismas víctimas. Así ocurrió, por ejemplo, con relación al compareciente Teniente Coronel (r) Gabriel de Jesús Rincón Amado, quien ya había sido condenado en la justicia ordinaria por casos de ejecuciones extrajudiciales o "falsos positivos" [116].

Rincón Amado se sometió a la JEP, habiendo sido condenado previamente a 46 años de prisión en la jurisdicción penal ordinaria ${ }^{[117]}$. Este compareciente recibió el beneficio de libertad transitoria condicionada y anticipada, previsto en la Ley 1820 de 2016 para agentes del Estado ${ }^{[118]}$, por parte de la Sala de Definición de Situaciones Jurídicas ${ }^{[19]}$. Ante esta circunstancia, la representante legal de una de las víctimas indirectas, madre de una de las personas ejecutadas, solicitó se declarara la nulidad de lo actuado, por violación al debido proceso, y presentó en contra de la decisión que concedió el beneficio los recursos de reposición y, en subsidio, de apelación. La Sección de Apelación del Tribunal para la Paz negó la solicitud de nulidad y confirmó el beneficio recibido por el compareciente ${ }^{[120]}$. Sin embargo, ordenó a la Sala de Definición de 
Situaciones Jurídicas realizar una audiencia "dialógica y participativa" que permitiera a la representante legal de la víctima indirecta a la que se ha hecho alusión, defender su tesis sobre falta de competencia de la JEP ${ }^{[121]}$. En esta audiencia — sobre la que se volverá más adelante—, realizada el 5 de marzo de 2019, se puso de presente que este mismo compareciente ya había sido citado por la Sala de Reconocimiento de Verdad en dos oportunidades y que había rendido versión voluntaria en el marco del caso 003 - sobre "muertes ilegítimamente presentadas como bajas en combate por agentes del Estado" - en sesiones de más de seis horas ${ }^{[122]}$. Vale anotar que, en el caso 003, para el 5 de marzo de 2019, se habían reconocido como intervinientes especiales 128 víctimas indirectas, dentro de las que se encuentran las cuatro víctimas que estaban presentes en la diligencia del 5 de marzo y que contaban con representación legal ante la Sala de Definición de Situaciones Jurídicas ${ }^{[123]}$.

La activación paralela de varios órganos de la JEP con relación al mismo compareciente ha sido explicada a partir de la forma como los casos pueden llegar a esta jurisdicción y con base en el principio de integralidad que la debe caracterizar ${ }^{[124]}$. Así lo aclaró uno de los magistrados de la Sala de Definición de Situaciones Jurídicas en audiencia de sometimiento y régimen de condicionalidad ${ }^{[125]}$, llevada a cabo el 10 de agosto de 2018, a la que asistieron 14 comparecientes, agestes del Estado, responsables por varios casos de ejecuciones extrajudiciales, entre los que se encontraba el Teniente Coronel (r) Rincón Amado ${ }^{[126]}$. Esta audiencia permite ver cómo varios casos llegan de la justicia ordinaria a la JEP de manera individual, probablemente con pocas víctimas identificadas, pero poco a poco comienzan a mostrar su verdadera complejidad, bien sea porque se trata del mismo responsable o porque comparten patrones criminales, lo que da lugar a su acumulación. ${ }^{[127]}$ Esta construcción progresiva de casos cada vez más complejos en el contexto de la JEP explica la posible activación simultánea de varios órganos de esta jurisdicción. Con relación a Rincón Amado, por ejemplo, en la audiencia del 10 de agosto su representante legal puso de presente la existencia, en total, de 14 procesos penales y 3 investigaciones disciplinarias adelantadas por la Procuraduría General de la Nación, todos estos trámites por hechos caracterizados como "falsos positivos" ${ }^{[128]}$. Entre estos se encuentra, precisamente, el proceso penal adelantado ante el Juzgado Primero Penal Especializado de Cundinamarca, en donde el 3 de abril de 2017 se profirió la sentencia condenatoria a 46 años de prisión.

Lo que parecen ser dos posibilidades procesales en la JEP — juzgamiento y concesión de beneficios-, aparentemente excluyentes entre sí, en realidad se pueden convertir entonces en fases o etapas que se suceden unas a otras, independientemente de la Sala ante la que se surte cada una. En este sentido, el Magistrado que dirigió la audiencia del 10 de agosto de 2018, mencionada en el párrafo anterior, explicó que en el caso de la Sala de Definición de Situaciones Jurídicas la jurisdicción se activa a partir de la solicitud de beneficios previstos en la Ley 1820 de 2016 y del monitoreo al régimen de condicionalidad ${ }^{[129]}$. Estos beneficios, señala el Magistrado, se comenzaron a otorgar desde el año 2017 en la jurisdicción penal ordinaria ${ }^{[130]}$. Es por esto que en estos casos "el proceso" inicia en la Sala de Definición de Situaciones Jurídicas, así el aporte a la verdad y la definición de la reparación se concreten en momentos posteriores, incluso ante otros órganos de la JEP ${ }^{[131]}$. La competencia de la Sala de Definición de Situaciones Jurídicas se activa, por consiguiente, con la concesión de beneficios individuales, en la medida en que existan procesos o condenas contra los comparecientes en la justicia ordinaria ${ }^{[132]}$. Como consecuencia, la Sala de Definición de Situaciones Jurídicas puede realizar en un primer momento un proceso de acumulación de casos - la situación de cada uno de los 14 comparecientes a esta audiencia llega a conocimiento de la Sala, justamente, de manera individual $-{ }^{[133]}$. Pero, una vez esta Sala ha recogido la información pertinente sobre los distintos procesos que existen o han existido en la jurisdicción penal ordinaria e identificado a las víctimas de los hechos de cada caso, debe ponerla en conocimiento de la Sala de Reconocimiento, para que allí se estudie dicha información desde la perspectiva de macrocriminalidad y macrovictimización ${ }^{[134]}$. En últimas, la Sala de Definición de Situaciones Jurídicas puede examinar lo relacionado con la privación de la libertad y los beneficios concedidos individualmente, de ser este el caso, 
mientras que la Sala de Reconocimiento se concentra, posteriormente y con un enfoque macro, en lo que aún no ha sido juzgado y no admite beneficios ${ }^{[135]}$.

La manera como hasta el momento se ha decantado el proceso penal con reconocimiento de responsabilidad en la JEP no solo se aleja de lo que se desprende del tenor literal de la LP-JEP, al estar dicho proceso, en la práctica, articulado con otras dimensiones de esta jurisdicción con las que en principio parecería incompatible, sino también al dar lugar a audiencias y diligencias no previstas expresamente en esta normatividad. A partir de los procesos observados para la elaboración de este artículo, se pueden identificar tres tipos de actuaciones procesales que no aparecen contempladas explícitamente en la LP-JEP y, no obstante, se han realizado o se van a realizar. Se trata de (i) audiencias que pueden ser consideradas mixtas al llevarse a cabo ante magistrados y magistradas de varias salas; (ii) de audiencias específicas para que las víctimas presenten ante la Sala de Reconocimiento observaciones sobre las versiones voluntarias; y (iii) audiencias en las que las víctimas rinden informes orales y entregan informes escritos a la Sala de Reconocimiento. Estas tres clases de diligencias han sido concebidas como desarrollo del principio dialógico y pretenden abrir espacios de diálogo entre los distintos actores de los procesos - jueces, víctimas y/o comparecientes-.

La audiencia realizada el 5 de marzo de 2019 por orden de la Sección de Apelación del Tribunal para la Paz con relación al compareciente Teniente Coronel (r) Rincón Amado tuvo lugar justamente ante la Sala de Definición de Situaciones Jurídicas y, al mismo tiempo, por disposición de la Sección de Apelación, de la Sala de Reconocimiento. Esta audiencia, inexistente en la estructura procesal definida en la LP-JEP, fue calificada como "dialógica y participativa" por la misma Sección ${ }^{[136]}$. Su objetivo era que la representante legal de unas de las víctimas expusiera las razones por las cuales consideraba que la JEP no era competente frente al homicidio del hijo de su representada, y que la Sala de Reconocimiento escuchara esta explicación ${ }^{[137]}$. Aunque la abogada se retractó y no hubo tal explicación ${ }^{[138]}$, la audiencia tuvo un carácter pedagógico importante, en la medida en que la Sala de Reconocimiento realizó varias explicaciones relacionadas con los avances del proceso 003, haciendo énfasis en las oportunidades de participación que tendrán las víctimas. Esta audiencia, en la que al final dos víctimas indirectas y sus representantes tuvieron oportunidad de expresar algunas de sus expectativas - sobre esto se volverá más adelante-, fue vista, además, como materialización de la noción de justicia restaurativa, tal como lo expresó uno de los magistrados, haciendo referencia a la sentencia C-007 de 2018 de la Corte Constitucional ${ }^{[139]}$.

En las explicaciones que dieron los magistrados de la Sala de Reconocimiento en esta audiencia se hizo alusión a la posibilidad de presentar en audiencia pública observaciones sobre las versiones voluntarias. Si bien el art. $27 \mathrm{D}$ (4) LP-JEP prevé la posibilidad de que las víctimas presenten observaciones sobre estas diligencias y reciban copia de los expedientes, la realización de audiencias públicas especialmente dirigidas a esta finalidad no está contemplada aquí. Sin embargo, según la explicación hecha por la Sala de Reconocimiento, las observaciones de las que trata el art. $27 \mathrm{D}(4)$ podrán darse por escrito u oralmente ${ }^{[140]}$. En este sentido, una Magistrada de esta Sala afirmó en la diligencia del 5 de marzo de 2019 que se programarán audiencias públicas para que las víctimas se pronuncien sobre las versiones voluntarias - es de recordar que, sin perjuicio de lo decidido en el auto del 28 de mayo de 2019, las víctimas no pueden asistir a estas versiones_ ${ }^{\text {[141] }}$ y, por ejemplo, puedan sugerir preguntas, para que en futuras citaciones la Sala se las formule a los comparecientes, o proponer aspectos puntuales sobre los que la Sala debería indagar, lo cual, en todo caso, debe ser evaluado por la Sala ${ }^{[142]}$. La Magistrada puntualizó, en consecuencia, que la Sala puede citar a versión voluntaria a los comparecientes cuantas veces sea necesario, atendiendo, por ejemplo, los requerimientos de las víctimas ${ }^{[143]}$.

Otra de las actuaciones no previstas expresamente en la LP-JEP como parte del proceso con reconocimiento y que han aparecido en cumplimiento del principio dialógico, además de la posibilidad de realizar audiencias mixtas y audiencias para presentar observaciones sobre versiones voluntarias, son los informes orales de víctimas que la Sala de Reconocimiento ha recibido como paso previo a la realización de versiones por parte de los comparecientes. Así ha ocurrido en el caso 001 sobre "retención ilegal de personas 
por parte de las FARC-EP”. Este caso se abrió con base en el informe No. 02 presentado por la FGN el 4 de julio de $2018^{[144]}$. Una vez se avocó conocimiento, la Magistrada Relatora notificó a 31 comparecientes, exintegrantes del Estado Mayor de las FARC, en audiencia pública realizada el 13 de julio del mismo año ${ }^{\text {[145] }}$ . Posteriormente, la Sala decidió citar a un grupo de políticos y familiares de políticos, cautivos por las FARC para canje con guerrilleros presos, con el fin de que rindieran informes mixtos, es decir escritos y orales, en sesión cerrada ${ }^{[146]}$. La presentación de informes orales generó un espacio de diálogo entre víctimas directas e indirectas y los magistrados y magistradas de la Sala de Reconocimiento - sin presencia de los comparecientes -, en el que las victimas contaron sus experiencias y la Sala tuvo la oportunidad de preguntar, desde detalles sobre su victimización hasta impresiones y expectativas sobre el cumplimiento de sus derechos en la JEP.

\section{Participación de víctimas e interacción con comparecientes y magistrados}

La necesidad de responder adecuadamente al principio dialógico también ha hecho que los magistrados y magistradas de la JEP asuman diferentes roles y que se generen distintas formas de interacción entre los sujetos procesales. En las audiencias observadas para la preparación de este trabajo se puede apreciar que la actitud asumida por quienes dirigen las diligencias promueve - consciente o inconscientemente- dos tipos de interacción entre los actores que intervienen en ellas, definiéndose así la dinámica preponderante: (i) manifestaciones de comparecientes y/o víctimas hacia los magistrados, buscando persuadirlos sobre sus propios puntos de vista, o (ii) comunicación directa entre comparecientes y víctimas. En otras palabras: la realización del principio dialógico al parecer depende en buena medida del rol que asumen los magistrados, quienes definen en últimas la dinámica de cada actuación procesal, y no tanto del diseño normativo del proceso $^{[147]}$.

Con relación al rol que asumen los magistrados, se pueden mencionar tres clases de actitudes que inciden en la dinámica dialógica de las diligencias. En algunas oportunidades se aprecia una actitud pedagógica ${ }^{[148]}$. Esta se observa en aquellos momentos en los que los magistrados explican a los intervinientes aspectos como la finalidad de cada audiencia, el desarrollo que han tenido o tendrán los procesos o los principios que los inspiran ${ }^{[149]}$. En otras ocasiones los magistrados se enfocan en controlar el cumplimiento de ciertos requisitos, o en exigir algunos comportamientos y/o cuestionar las actuaciones, por ejemplo, de los comparecientes ${ }^{[150]}$. Además, también se ha observado una actitud más o menos pasiva, en la que los magistrados y magistradas escuchan atentamente las declaraciones, sobre todo, de las víctimas ${ }^{[151]}$. La primera actitud, podría decirse, puede contribuir a que se den verdaderos diálogos entre comparecientes y víctimas, puesto que estas explicaciones dan claridad a los sujetos procesales e intervinientes sobre lo que se espera de ellos y sobre lo que ellos, al menos en principio, pueden esperar de los procesos ${ }^{[152]}$. La tercera actitud también es positiva desde la perspectiva del principio dialógico, ya que ha permitido un acercamiento con las víctimas alrededor de aspectos que trascienden lo estrictamente relevante con miras a la determinación de la responsabilidad penal, así como manifestaciones de empatía para con ellas ${ }^{[153]}$. En cambio, la segunda actitud aparentemente no corresponde a la noción de proceso dialógico, pues en estas ocasiones la dinámica de las audiencias tiende a tornarse confrontacional, aunque es razonable suponer que dicha noción no necesariamente es compatible con todas las decisiones que se deben tomar a lo largo del proceso ${ }^{[154]}$.

Desde el punto de vista de la comunicación entre quienes intervienen en las diligencias, se han dado entonces casos en los que la interacción ocurre principalmente entre los sujetos procesales y los magistrados y magistradas. Es decir, situaciones en las que en realidad no hay diálogo entre comparecientes y víctimas, sino más bien expresión de opiniones, de preocupaciones, manifestaciones de voluntad, formulación de preguntas, etc., dirigidas a quienes presiden cada actuación procesal ${ }^{[155]}$. El intercambio entre comparecientes y victimas está en estos casos mediado por los jueces y juezas. En otras ocasiones, aunque hasta ahora, al parecer, han sido 
pocas, sí ha habido cierta interacción directa entre comparecientes y víctimas. Estas últimas han tenido, por ejemplo, la oportunidad de formular preguntas directamente a los comparecientes o de expresar su opinión sobre lo que aquellos han propuesto. ${ }^{[156]}$

El carácter dialógico del proceso podría limitarse entonces únicamente a que los magistrados y magistradas tuvieran en cuenta la opinión de comparecientes y víctimas en la toma de decisiones, garantizando espacios de participación para escucharlos. Desde esta perspectiva, la víctima efectivamente podría jugar un papel relevante en el proceso, pero principalmente como fuente de información. Sin embargo, otra posibilidad es entender el carácter dialógico de una manera más amplia, en la que comparecientes y víctimas no solamente intervengan para exponer sus puntos de vista ante los magistrados, sino que lo hagan interactuando entre ellos. Esta posibilidad supone que haya verdaderos diálogos entre comparecientes y víctimas, mediados, si se quiere, por los magistrados y magistradas de la JEP, pero orientados, no tanto a la persuasión de los jueces y juezas, sino más bien a la construcción de acuerdos. Aunque aún es prematuro realizar una valoración general, al parecer la práctica de la JEP en el proceso con reconocimiento de responsabilidad se está inclinando poco a poco hacia la segunda alternativa. Esto, se debe decir, encuentra fundamento no solamente en el art. 1 (b) LP-JEP, en donde se caracteriza el proceso con reconocimiento como "dialógico o deliberativo" -lo cual, considerado aisladamente, se podría satisfacer dando suficientes espacios de participación a las víctimas- ${ }^{[157]}$, sino también en el art. 27, en el que se establece el deber de las salas y secciones de la JEP de promover "la construcción de acuerdos [...] en todas las fases del procedimiento" (cursivas añadidas).

En las intervenciones que se han dado en las audiencias, tanto en los casos en que la comunicación se da entre los sujetos procesales y los magistrados y magistradas, como en los casos en que ha habido cierto diálogo entre comparecientes y víctimas, se han puesto de presente algunos aspectos del proceso con reconocimiento que se deben reseñar para intentar dimensionar su carácter dialógico, sobre todo con miras a los retos que se podrán enfrentar en etapas futuras que aún no se han desarrollado. Interesa resaltar el enfoque de justicia restaurativa acogido por los magistrados y magistradas, así como las nociones de verdad y reparación que se han ventilado tanto por ellos como por comparecientes y víctimas. Estas opiniones permiten plantear varios interrogantes sobre la dinámica que tomarán las audiencias cuya existencia está prevista en la LP-JEP, y sobre el tipo de audiencias y diligencias que se realizarán en el futuro cercado, dentro del margen de maniobra que la LP-JEP concede a magistrados y magistradas, sin que se haya contemplado previamente su existencia.

En las audiencias que se llevaron a cabo el 10 de agosto de 2018 y el 5 de marzo de 2019 los magistrados hicieron alusión a la idea de justicia restaurativa, como paradigma orientador de la JEP ${ }^{[158]}$. En las dos oportunidades se definió este paradigma en los mismos términos utilizados en el Acuerdo de Paz con referencia al SIVJRNR, es decir, por un lado, como "restauración del daño causado" y "reparación de las víctimas afectadas por el conflicto" y, por otro lado, como terminación de la "situación de exclusión social" que haya provocado la victimización ${ }^{[159]}$. Así definidos los objetivos de la justicia restaurativa en el contexto de la JEP, es posible identificar en ella dos dimensiones: una individual -reparación del daño causado a la víctima- y una colectiva -transformación de circunstancias sociales excluyentes-. Si el proceso con reconocimiento de verdad en la JEP está orientado por estas dos finalidades, cabe preguntarse cuál será su aporte, como componente del SIVJRNR, sobre todo con miras al segundo objetivo, es decir, ¿̇se deberán discutir aspectos de política social, nacionales y/o locales en desarrollo de este proceso?, ¿tendrán que acudir, bien sea como sujetos procesales o como testigos, representantes de entidades estatales responsables de este tipo de políticas?, ¿se podrán tomar por parte de la JEP decisiones judiciales que impacten la política social? Todos estos aspectos van más allá de la "simple" discusión sobre la responsabilidad penal individual y la reparación del daño concreto causado con el delito y no es claro cómo se podrán discutir en un proceso judicial pensado principalmente para sancionar -aunque con enfoque reparador- la comisión de crímenes graves cometidos masivamente.

Un aspecto fundamental en la idea de justicia restaurativa traída a colación en las audiencias observadas es la construcción de verdad. Esta, vale decirlo, constituye una forma de reparación, en la que las dimensiones 
individual y colectiva también se pueden identificar. En las audiencias del 10 de agosto de 2018 y del 5 de marzo de 2019 se habló, por consiguiente, de "verdad plena”. En la primera, el Magistrado que la presidía se refirió a esta idea parafraseando los términos en que es definida en el Acuerdo de Paz y las normas que lo desarrollan ${ }^{[160]}$, la cual incluye el relato "exhaustivo y detallado de las conductas cometidas y las circunstancias de su comisión", así como la información "necesaria y suficiente para atribuir responsabilidades" [161]. En la segunda, sin embargo, se aclaró que la construcción de "verdad plena” supone ir más allá de los hallazgos que ya ha hecho la justicia penal ordinaria, para descubrir patrones macrocriminales y encontrar explicaciones generales de las violaciones de derechos humanos, pero sin perder vista el caso concreto ${ }^{[162]}$. En consecuencia, en las audiencias se debería intentar conciliar estas dos visiones sobre la verdad -individual y colectiva- y las actuaciones de los magistrados tendrían entonces que estar acorde con esta tarea, ordenando, por ejemplo, la práctica de pruebas, formulando preguntas, etc., que atiendan a estas dos facetas de la historia del conflicto armado. Podría agregarse, además, que la idea de "verdad plena" también debería incluir un análisis de causas sociales de la violencia, con el fin de contar con una base fáctica que soporte la reparación, entendida como terminación de la "situación de exclusión social". No obstante, es difícil ignorar que esto excede los límites de un mecanismo judicial de justicia transicional creado para establecer responsabilidades individuales.

Las víctimas -y sus representantes- han coincidido, en términos generales, con esta doble visión sobre la verdad. En este sentido, por ejemplo, en la audiencia del 10 de agosto de 2018 uno de los representantes de víctimas insistió en que la verdad es la "columna vertebral" de la justicia, pero refiriéndose a una verdad completa, en la que se identifique a todos los que participaron en los hechos victimizantes $^{[163]}$. En esta intervención, incluso, se pidió que las víctimas tuvieran acceso a los archivos de las instituciones comprometidas con estos crímenes ${ }^{[164]}$. Otro representante de víctimas se refirió en esta diligencia a la importancia de "dar razón de los máximos responsables" y de las "políticas que animaron este tipo de crímenes" -la audiencia, vale recordarlo, se realizó en el marco del proceso 003 sobre ejecuciones extrajudiciales- ${ }^{[165]}$. La pretensión de que los “máximos responsables" o "altos mandos" sean llamados ante la JEP a "rendir cuentas" aparece también en las intervenciones de algunas víctimas indirectas que tuvieron la oportunidad de manifestarse tanto en la audiencia del 10 de agosto de 2018 como en la del 5 de marzo de $2019^{[166]}$.

La doble dimensión de la verdad como elemento fundamental de la reparación ${ }^{[167]}$ también aparece en los informes orales rendidos ante la Sala de Reconocimiento por víctimas directas e indirectas de secuestro en el caso 001. La pretensión de verdad de las víctimas en este caso es particular, ya que no solamente involucra aspectos colectivos sobre el grupo responsable de la victimización, es decir las FARC -por ejemplo, sobre la responsabilidad del Estado Mayor de ese grupo insurgente por la política de cometer secuestros- ${ }^{[168]}$, y aspectos individuales sobre las vivencias de las víctimas en el día a día de su cautiverio -por ejemplo, sobre el trato que recibían, condiciones de salud, alimentación, etc.- ${ }^{[169]}$, sino también aspectos a aclarar con relación a la actitud del Estado o funcionarios públicos antes, durante y después de estos hechos. Así sucedió, por ejemplo, en los casos de Ingrid Betancourt y Clara Rojas ${ }^{[170]}$, y en el de los diputados del Valle ${ }^{[171]}$. Es decir, la discusión propuesta por las víctimas en este caso supera la relación víctima-victimario construida alrededor del crimen e involucra cuestiones relacionadas con otras formas de victimización, entre ellas, por ejemplo, la desatención o descuido del Estado ante situaciones de riesgo para la vida de los ciudadanos y ciudadanas.

Con relación a otras formas de reparación, en las diligencias observadas han surgido ideas diversas, incluso con miras a la imposición de sanciones propias ${ }^{[172]}$. Se han visto víctimas -directas o indirectas- que esperan la imposición de sanciones severas a los responsables y en este sentido apelan a que se haga "justicia" como forma de satisfacción ${ }^{[173]}$, hasta víctimas que piden se ordene la realización de obras con contenido social por parte, por ejemplo, de las FARC, como la construcción de casas o colegios ${ }^{[174]}$. También se ha hecho alusión a formas simbólicas de reparación, como la construcción de monumentos para preservar la memoria ${ }^{[175]}$. Otra forma 
de reparación mencionada son las manifestaciones de arrepentimiento ${ }^{[176]}$, aunque es interesante señalar que en este sentido una de las víctimas indirectas de secuestro afirmó esperar este tipo de gestos, no por parte de altos mandos de las FARC -que probablemente nunca vieron a su padre-, sino de las personas con quien este compartía la cotidianidad ${ }^{[177]}$. En algunas diligencias se ha puesto de presente, de todas maneras, que la reparación, incluso como componente de la sanción propia, debe ser definida de manera "mancomunada" con la participación de comparecientes y víctimas, precisamente, en virtud del principio dialógico ${ }^{[178]}$.

Con fundamento en el principio dialógico, los comparecientes también han tenido oportunidad de manifestarse sobre la reparación. Sin embargo, en varias ocasiones sus declaraciones al respecto han sido bastante generales y se han limitado a reiterar el compromiso, en abstracto, de contribuir a la verdad, a la reparación y a la no repetición. En la audiencia del 10 de agosto de 2018, por ejemplo, de catorce comparecientes a los que se les preguntó sobre propuestas de reparación, solamente uno, el Teniente Coronel ( $r$ ) Rincón Amado, hizo una propuesta concreta, refiriéndose a la participación en una cátedra por la paz, en la que contaría sus experiencias en el conflicto armado, como forma de contribuir a la no repetición ${ }^{[179]}$.

Tal vez un ejemplo sobre la construcción dialógica de las medidas de reparación se puede encontrar en la audiencia realizada el 28 de noviembre de 2018 ante la Sala de Definición de Situaciones Jurídicas con relación a la "masacre de Mondoñedo" -la cual puede orientar actuaciones posteriores de la Sala de Reconocimiento relacionadas con la determinación de la sanción propia-. En esta diligencia los comparecientes realizaron propuestas concretas de reparación, de las cuales se corrió traslado a las víctimas indirectas, para que estas manifestaran en la audiencia sus opiniones ${ }^{[180]}$. Entre las propuestas se hizo alusión a capacitaciones en las escuelas militares, narrando los hechos ocurridos en la masacre de Mondoñedo y mostrando quiénes eran realmente las víctimas ${ }^{[181]}$; también se habló de elaborar cartillas, de ceremonias conmemorativas de las víctimas, de realizar foros y conferencias con miembros de las Fuerzas Armadas en los que se expondrían las circunstancias en las que se produjo la muerte de las víctimas, sobre la tragedia que los hechos victimizantes generaron en sus familiares y sobre la importancia de respetar los derechos fundamentales ${ }^{[182]}$. Al final de la diligencia, de todas maneras, hubo cierto reproche debido a la falta de concreción de las propuestas hechas por los comparecientes y se llamó la atención sobre la importancia de construir planes de reparación más específicos y estructurados ${ }^{[183]}$. Aunque los alcances de la reparación -y, en consecuencia, de la sanción propia en casos de reconocimiento de responsabilidad-constituye un aspecto que se deberá decantar de forma dialógica a medida que los procesos avanzan, cabe preguntarse qué tanto coinciden las expectativas de las víctimas en este punto con lo que están dispuestos y pueden ofrecer los comparecientes y si eventuales desacuerdos podrán afectar el carácter dialógico de las diligencias y fomentar dinámicas más adversariales.

\section{Consideraciones finales: retos del derecho penal en contextos de justicia transicional}

Los interrogantes a los que da lugar la LP-JEP, aunados a las vicisitudes de los procesos en la práctica, ponen de presente varios retos a los que se enfrenta el derecho penal en contextos de justicia transicional. En Colombia estos retos surgen, además, al adoptarse nociones orientadoras del proceso como las de justicia restaurativa y principio dialógico, lo cual lleva a que el proceso y el derecho penal deban responder al mismo tiempo a objetivos diversos ${ }^{[184]}$. Con el fin de dimensionar la complejidad del asunto, es necesario, en primer lugar, tratar de definir la relación entre los objetivos tradicionales del proceso penal y los objetivos más generales de la justicia transicional. De esta manera, es posible identificar con mayor claridad algunas de las dificultades que enfrenta la persecución penal en este tipo de contextos.

En primer lugar, se debe precisar que es necesario el cumplimiento de los objetivos tradicionales del proceso penal para alcanzar los objetivos particulares que se persiguen en contextos de justicia transicional. Por lo 
tanto, el cumplimiento de los primeros se puede entender como condición para que los mecanismos judiciales de justicia transicional sean efectivos, desde el punto de vista de su finalidad más general: construcción de paz mediante el fortalecimiento del Estado de Derecho ${ }^{[185]}$. Así, por ejemplo, el objetivo de proporcionar seguridad jurídica y de reafirmar la vigencia del derecho no son solo objetivos relevantes en el proceso penal ordinario. Ellos también juegan un papel fundamental desde el punto de vista de la justicia transicional. De ahí que en el Acuerdo de Paz se haya hecho referencia precisamente a la seguridad jurídica y a la lucha contra la impunidad al hablar de la JEP ${ }^{[186]}$.

A pesar de las particularidades del proceso con reconocimiento de responsabilidad, por consiguiente, en este contexto no se le debe restar relevancia a la necesidad de corroborar la veracidad de los hechos que sustentarán las condenas. Tampoco se debe subestimar la necesidad de proveer suficientes espacios de defensa a los comparecientes y, en general, de participación a los sujetos procesales e intervinientes ni de emitir providencias bien fundamentadas fáctica y jurídicamente, que tengan vocación de estabilidad. La forma como se concrete el principio dialógico no debería entonces oponerse a esto. De hecho, la LP-JEP prevé algunas actuaciones que apuntan justamente a la materialización de estos objetivos, como, por el ejemplo, el análisis que según el art. $27 \mathrm{~B}$ debe realizar la Sala de Reconocimiento del acervo probatorio y las versiones voluntarias ${ }^{[187]}$ o la evaluación de correspondencia que, según el art. 29, le corresponde adelantar a la Sección de Primera Instancia del Tribunal para la Paz ${ }^{[188]}$. Aunque, se debe decir, los vacíos o ambigüedades de la misma LP-JEP, como la incertidumbre que los art. 27 A, 27 B y 27 C generan sobre el reconocimiento de responsabilidad ${ }^{[189]}$, afectan la seguridad sobre las reglas de juego. El margen de maniobra que esta ley deja a los magistrados tendrá que utilizarse entonces no solamente para innovar sobre la estructura del proceso, en atención a sus principios, sino también para aclarar aspectos como este que inciden en la confianza sobre sus actuaciones.

Además de atender a los objetivos tradicionales del proceso penal, al constituir un mecanismo de justicia transicional, el proceso con reconocimiento de responsabilidad en la JEP también debe responder a otro tipo de objetivos. En este contexto el proceso está llamado a adquirir una relevancia especial, dado su poder expresivo ${ }^{[190]}$. Sin embargo, la forma como este proceso fue diseñado en la LP-JEP no permite ver con claridad cómo esto se debe dar en la práctica. Por esta razón, las audiencias o actuaciones que se han realizado y/ o, se supone, se van a realizar, pero que no están previstas expresamente en la LP-JEP, son especialmente relevantes. Así ocurre, por ejemplo, con la posibilidad de realizar audiencias conjuntas entre varios órganos de la jurisdicción ${ }^{[191]}$, con las audiencias de observaciones a las versiones voluntarias, cuya realización se anunció por parte de la Sala de Reconocimiento ${ }^{[192]}$, e incluso con la presentación de informes orales por parte de las víctimas ${ }^{[193]}$. Es sobre todo en este tipo de escenarios que el principio dialógico, entendido como interacción entre comparecientes y víctimas, puede encontrar su mayor expresión. Aunque, de todas maneras, queda abierta la pregunta sobre el alcance temático que tendrán estas y las demás diligencias, dado que, como ya se mencionó, la JEP está cruzada por una doble perspectiva sobre los crímenes a juzgar.

En contextos de justicia transicional, la persecución penal de violaciones masivas de derechos humanos adquiere una doble perspectiva: colectiva o macro e individual o micro ${ }^{[194]}$. Esto se ha reflejado en lo dicho en distintas diligencias tanto por los magistrados y magistradas como por los sujetos procesales e intervinientes. No obstante, pareciera que algunas normas y en ocasiones algunos órganos privilegiaran la perspectiva colectiva $^{[195]}$, mientras que puede haber víctimas que acudan a la JEP esperando la satisfacción de sus derechos individuales. Esta circunstancia permite preguntarse cuál perspectiva primará al definir, por ejemplo, aquello que se probará, la clase de fundamentos de la responsabilidad penal que se requerirán para condenar, el tipo de daño que se tendrá que reparar, así como las medidas de reparación -incluso como parte de la sanción propia-. El alcance del principio dialógico podrá depender de la manera como se resuelva esta tensión. Si la intención es establecer patrones macrocriminales, que permitan reconstruir y entender contextos de violencia masiva, identificando características comunes entre las víctimas ${ }^{[196]}$, así como las condiciones sociales que 
contribuyeron a estos fenómenos de violencia ${ }^{[197]}$, probablemente el principio dialógico supondrá escuchar a los comparecientes y a algunas víctimas, pero será difícil implementar metodologías de diálogo e interacción directa novedosas entre los protagonistas de los hechos victimizantes puntuales, o al menos esto se hará de manera muy selectiva. Al mismo tiempo, privilegiar la perspectiva individual -lo que en estricto sentido parecería más coherente con la noción de justicia restaurativa-, en procesos de esta envergadura, en los que el número inicial de comparecientes puede llegar a ser, por ejemplo, de 2000 personas ${ }^{[198]}$, o en los que la Sala de Reconocimiento puede tener que enfrentarse a una sola solicitud de acreditación de víctimas que involucra a 600 personas ${ }^{[199]}$, puede ser poco realista.

En las audiencias se ha llamado la atención, en todo caso, sobre la importancia de equilibrar estas dos perspectivas. La pregunta es cómo se hará compatible lo dicho, por ejemplo, en el art. 27 LP-JEP sobre construcción de la verdad y determinación de la sanción dialógicamente, con la perspectiva de macrocriminalidad y con la noción colectiva o social de justicia restaurativa adoptada en el Acuerdo de Paz, sin perder de vista, como se ha insistido a lo largo de este artículo, los objetivos más tradicionales del proceso penal. El principio dialógico constituye entonces un aspecto directamente relacionado con la estructura y el alcance del proceso con reconocimiento de responsabilidad en la JEP, cuyas implicaciones reales aún están por definirse; la manera como esta ocurra tendrá consecuencias sobre la medida en que se responderá, en últimas, a las expectativas de las víctimas.

\section{Bibliografía}

Acto Legislativo 01 de 2017 [Congreso de Colombia]. Por medio del cual se crea un título de disposiciones transitorias de la constitución de una paz estable y duradera y se dictan otras disposiciones. 4 de abril de 2017.

Acuerdo Final de Paz [Gobierno Nacional y FARC-EP]. Acuerdo final para la terminación del conflicto y la construcción de una paz estable y duradera. 12 de noviembre de 2016. https://www.cancilleria.gov.co/sites/def ault/files/Fotos2016/12.11_1.2016nuevoacuerdofinal.pdf

Alejandro David Aponte, Título II, Capítulo I: Objeto y ámbito de aplicación, en Ley de Amnistía. Comentario completo y sistemático (Ley 1820 de 2016) (Kai Ambos \& Gustavo Cote eds., Temis, Bogotá 2019).

Christoph Safferling, Internationales Strafrecht (Springer, 2011). https://doi.org/10.1007/978-3-642-14914-6

Corte Constitucional de Colombia. Sentencia C-007 de 2018 (M. P. Diana Fajardo Rivera; 1 de marzo de 2018).

Corte Constitucional de Colombia. Sentencia C-080 de 2018 (M. P. Antonio José Lizarazo Ocampo;15 de agosto de 2018.

Corte Constitucional de Colombia. Sentencia C-409 de 2009 (M. P. Juan Carlos Henao Pérez; 17 de junio de 2009.

Corte Constitucional de Colombia. Sentencia C-674 de 2017 (M. P. Luis Guillermo Guerrero Pérez;14 de noviembre de 2017).

Corte Constitucional de Colombia. Sentencia C-979 de 2005 (M. P. Jaime Córdoba Triviño; 26 de septiembre de 2005.

Dalia Magally Morales Vallecilla, Secretaria Sala de Reconocimiento de Verdad y Responsabilidad y Determinación de los Hechos y Conductas, Oficio No. OSJ-SRVR-01033, 29 de marzo de 2019.

Diccionario de la Real Academia de la Lengua Española (RAE). https://dle.rae.es/?w=deliberar

Diego Fernando Tarapués Sandino, Artículo 15. Amnistía “de iure”, en Ley de Amnistía. Comentario completo y sistemático (Ley 1820 de 2016) (Kai Ambos \& Gustavo Cote eds., Temis, Bogotá 2019).

Diego Fernando Tarapués Sandino, Artículo 23. Criterios de conexidad, en Ley de Amnistía. Comentario completo y sistemático (Ley 1820 de 2016) (Kai Ambos \& Gustavo Cote eds., Temis, Bogotá 2019).

Eduard Kern \& Claus Roxin, Strafverfahrensrecht (11.. ed., 1972).

Friedrich-Christian Schroeder, Strafprozeßrecht (C.H. Beck, 1993). 
Gerhard Werle \& Moritz Vormbaum, Transitional Justice. Vergangenheitsbewältigung durch Recht (Springer, 2018). https://doi.org/10.1007/978-3-662-55676-4

Gustavo Emilio Cote Barco, Artículo 46. De la renuncia a la persecución penal, en Ley de Amnistía. Comentario completo y sistemático (Ley 1820 de 2016) (Kai Ambos \& Gustavo Cote eds., Temis, Bogotá 2019).

Herbert Jäger, Makrokriminalität: Studien zur Kriminologie kollektiver Gewalt (Suhrkamp Verlag 1989).

Howard Zehr, Changing Lenses: A New Focus for Crime and Justice (Herald Press, 1990). https://www.youtube.co $\mathrm{m} /$ watch?v=yoKhg7c3YGQ\&list=PLbtegW3d3L4JAstPux8ji9-h9balFGI6M

Howard Zehr \& Ali Gohar, The Little Book of Restorative Justice (2003). https://www.unicef.org/tdad/littlebookr jpakaf.pdf

I Carolyn Hoyle, General Introduction, en Restorative Justice. Critical Concepts in Criminology (Routledge, 2010).

III Kai Ambos, Treatise on International Criminal Law: International Criminal Procedure (Oxford University Press, 2016).

Iván Orozco, Justicia transicional en tiempos del deber de memoria (Temis-Universidad de los Andes, 2009).

JEP Colombia, Audiencia de alegatos y decisión final del régimen de condicionalidad sobre 'El Paisa', realizada por la Sala de Reconocimiento el 26 de abril de 2019. YouTube. https://www.youtube.com/watch?v=JC8NO134DpM

JEP Colombia, Audiencia de manifestación voluntaria de sometimiento del General ( $r$ ) del Ejército Nacional de Colombia, Mario Montoya, ante la Sala de Definición de Situaciones Jurídicas, realizada el 13 de septiembre de 2018. YouTube. https://www.youtube.com/watch?v=FAmaTx4lNbU\&list=PLbtegW3d3L4JAstPux8ji9-h9b alFGI6M\&index $=8$

JEP Colombia, Audiencia de régimen de condicionalidad a miembros del GAULA del Ejército ante la Sala de Definición de Situaciones Jurídicas, realizada el 30 de agosto de 2018. YouTube. https://www.youtube.com/watch?v=ZKey Tjuj05k\&list=PLbtegW3d3L4JAstPux8ji9-h9balFGI6M\&index=12

JEP Colombia, Audiencia de régimen de condicionalidad ante la Sala de Definición de Situaciones Jurídicas, realizada en San Gil (Santander), 15 de noviembre de 2018. YouTube. https://www.youtube.com/watch?v=UoQwxCMYJ GQ\&list=PLbtegW3d3L4JAstPux8ji9-h9balFGI6M\&index=7

JEP Colombia, Audiencia de régimen de condicionalidad, Mondoñedo II, realizada ante la Sala de Definición de Situaciones Jurídicas el 28 de noviembre de 2018. YouTube. https://www.youtube.com/watch?v=h_tddODdjs o\&list=PLbtegW3d3L4JAstPux8ji9-h9balFGI6M\&index=5

JEP Colombia, Audiencia de régimen de condicionalidad, Mondoñedo III, realizada ante la Sala de Definición de Situaciones Jurídicas el 28 de noviembre de 2018. YouTube. https://www.youtube.com/watch?v=VPiC9yuIdT Q\&list=PLbtegW3d3L4JAstPux8ji9-h9balFGI6M\&index $=4$

JEP Colombia, Audiencia de régimen de condicionalidad por la masacre de Mondoñedo (Cundinamarca), Mondoñedo I, realizada ante la Sala de Definición de Situaciones Jurídicas el 18 de noviembre de 2018, primera parte. YouTube. h ttps://www.youtube.com/watch?v=6S-j34I6qYs\&list=PLbtegW3d3L4JAstPux8ji9-h9balFGI6M\&index=6

JEP Colombia, Audiencia de sometimiento de los ex integrantes del Estado Mayor y del Secretariado de las FARC-EP ante la Sala de Reconocimiento parte 1, realizada el 13 de julio de 2018. YouTube. https://www.youtube.com/wa tch?v=ATurqqdaWDI\&list=PLbtegW3d3L4JAstPux8ji9-h9balFGI6M\&index=13

JEP Colombia, Audiencia de sometimiento de los ex integrantes del Estado Mayor y del Secretariado de las FARC-EP ante la Sala de Reconocimiento parte 2, realizada el 13 de julio de 2018. YouTube. https://www.youtube.com/wa tch?v=F9FCXq1wAX0\&list=PLbtegW3d3L4JAstPux8ji9-h9balFGI6M\&index=14

JEP Colombia, Audiencia de sometimiento y régimen de condicionalidad en el 'Caso Soacha' ante la Sala de Definición de Situaciones Juridicas, realizada el 10 de agosto de 2018. YouTube. https://www.youtube.com/watch?v=n42MK 3G_RTA\&list=PLbtegW3d3L4JAstPux8ji9-h9balFGI6M\&index $=11$

JEP Colombia, Audiencia del coronel (r) Gabriel de Jesús Rincón Amado del Ejército Nacional de Colombia, realizada por magistrados de la Sala de Definición de Situaciones Jurídicas junto con magistrados de la Sala de Reconocimiento el 5 de marzo de 2019. YouTube. 
JEP Colombia, Informe oral de Clara Rojas ante la Sala de Reconocimiento. YouTube. https://www.youtube.com/w atch?v=tkBVrLsxUnY

JEP Colombia, Informe oral de Luis Mendieta ante la Sala de Reconocimiento. YouTube. https://www.youtube.com/ watch? $=\mathrm{BFJg} 2 \mathrm{vO}$ sgWI

JEP Colombia, Informe oral presentado por Ingrid Betancourt ante la Sala de Reconocimiento. YouTube. https://www .youtube.com/watch?v=6RdEgrWCmDE

JEP Colombia, Informes orales de familiares de Diputados del Valle. YouTube. https://www.youtube.com/watch?v=j xNxST8nfLA

JEP Colombia, Sala de Reconocimiento de Verdad, de Responsabilidad y de Determinación de los Hechos y Conductas, Auto 080 del 28 de mayo de 2019.

Joanna R. Quinn, The Development of Transitional Justice, en Research Handbook on Transitional Justice, 11-33 (Cheryl Lawther, Luke Moffett \& Dov Jacobs eds., 2017).

Juana Inés Acosta López \& Carlos Enrique Arévalo Narváez, en Ley de Amnistía. Comentario completo y sistemático (Ley 1820 de 2016), 110-121 (art. 10), 150-166 (art. 14), 347-357 (art. 33) y 491-502 (art. 50) (Kai Ambos \& Gustavo Cote eds., Temis, Bogotá 2019). https://www.kas.de/documents/271408/4530743/Comentario+completo+y+sistem\%C3\%A1tico+a + la+Ley+de+Amnist\%C3\%ADa+colombiana.pdf/79910d44-d10f-faf3-0ebb-f15aef0b6e71 ?version=1.0\&t $=$ 1555432143901

Julieta Lemaitre Ripoll, Magistrada, Sala de Reconocimiento de Verdad y Responsabilidad y Determinación de los Hechos y Conductas, Oficio No. SRVR-00325, 27 de marzo de 2019.

Jurisdicción Especial para la Paz, Orientaciones para la presentación de informes. https://www.jep.gov.co/Infografas/c artilla-guia-rientacion-para-elaboracion-de-informes-cot-62000.pdf

Jurisdicción Especial para la Paz, Sala de Reconocimiento de Verdad, de Responsabilidad y de Determinación de los Hechos y Conductas, Criterios y metodología de priorización de casos y situaciones, 28 de junio de 2018, disponible en: https://www.jep.gov.co/Documents/CriteriosYMetodologiaDePriorizacion.pdf (última consulta: 01.09.2019).

Klaus Volk \& Armin Engländer, Grundkurs StPO, (9. ed., C.H. Beck, 2018).

Ley 1820 de 2016. Por medio de la cual se dictan disposiciones sobre amnistía, indulto y tratamientos penales especiales y otras disposiciones. 30 de diciembre de 2018. D. O. 50102.

Ley 1922 de 2018. Por medio de la cual se adoptan unas reglas de procedimiento para la Jurisdicción Especial para la Paz. 18 de julio de 2018. D. O. 50658.

Ley 906 de 2004. Por la cual se expide el Código de Procedimiento Penal. 31 de agosto de 2004. D. O. 45658.

Ley (Estatutaria) 1957 de 2019. Estatutaria de la Administración de Justicia en la Jurisdicción Especial para la Paz. 6 de junio de 2019. D. O. 50976.

María del Pilar Bahamón Falla, Secretaría Ejecutiva, Jurisdicción Especial para la Paz, Oficio No. 201961220349981, 7 de marzo de 2019.

Mónica Cifuentes Osorio, Procuradora Delegada con funciones de coordinación de intervención para la Jurisdicción Especial para la Paz, Concepto No. 019-2019-6CHC-1IJP, 2 de abril de 2019.

Nadiezdha Henriquez Chacín, Magistrada, Sala de Reconocimiento de Verdad y Responsabilidad y Determinación de los Hechos y Conductas, Oficio No. 20193240172781, 30 de abril de 2019.

Nandor Knust, Strafrecht und Gacaca. Entwicklung eines pluralistischen Rechtsmodell am Beispiel des ruandischen Völkernmordes (Duncker \& Humblot, 2013).

Oscar Parra Vera, presidente, Sala de Reconocimiento de Verdad y Responsabilidad y Determinación de los Hechos y Conductas, Oficio No. 20193210194011, 13 de mayo de 2019.

Randy E. Barnett, Restitution. A new paradigm of criminal justice, en Restorative Justice. Critical Concepts in Criminology, 34-56 (Carolyn Hoyle Ed., Routledge, 2010). 
Tribunal para la Paz, Sección de Apelación, Sentencia Interpretativa TP-SA-SENIT 1 de 2019, sobre beneficios provisionales, régimen de condicionalidad y participación de víctimas, 3 de abril de 2019.

United Nations, Security Council, The Rule of Law and Transitional Justice in Conflict and Post-Conflict Societies, Report of the Secretary-General, 23.08.2004 (doc: S/2004/616).

Urs Kindhäuser \& Kay H. Schumann, Strafprozessrecht (5.. ed., 2019).

\section{Notas}

[1] ver Acuerdo Final de Paz [Gobierno Nacional y FARC-EP]. Acuerdo final para la terminación del conflicto y la construcción de una paz estable y duradera. 12 de noviembre de 2016. También art. transitorio 1 (primer párrafo) Acto Legislativo (AL) 01 de 2017.

[2] Art. transitorio 5 (primer párrafo) AL 01 de 2017.

[3] Acuerdo Final de Paz, op. cit., 145 (núm. 9, primer párrafo); art. transitorio 5 (primer párrafo) AL 01 de 2017.

[4] De acuerdo con la Ley de Amnistía, en el marco del Acuerdo de Paz es posible conceder beneficios como la amnistía para miembros de las FARC, o la renuncia a la persecución penal, para agentes del Estado. Ver art. 15, 21 y 46 de la Ley de Amnistía. Al respecto ver Diego Fernando Tarapués Sandino, Artículo 15. Amnistía “de iure”, en Ley de Amnistía. Comentario completo y sistemático (Ley 1820 de 2016), 169-173 (Kai Ambos \& Gustavo Cote eds., Temis, Bogotá 2019); Gustavo Emilio Cote Barco, Artículo 46. De la renuncia a la persecución penal, en Ley de Amnistía. Comentario completo y sistemático (Ley 1820 de 2016), 439-467 (Kai Ambos \& Gustavo Cote eds., Temis, Bogotá 2019).

[5] Ver art. 10, 14, 18, 33, 35 (parágrafo) y 50 Ley de Amnistía; al respecto ver comentarios de Juana Inés Acosta López \& Carlos Enrique Arévalo Narváez, en Ley de Amnistía. Comentario completo y sistemático (Ley 1820 de 2016), 110-121 (art. 10), 150-166 (art. 14), 347-357 (art. 33) y 491-502 (art. 50), (Kai Ambos \& Gustavo Cote eds., Temis, Bogotá 2019). También art. transitorio 18 AL 01 de 2017. Sobre el régimen de condicionalidad ver Corte Constitucional de Colombia, Sentencia C-007 del 1 de marzo de 2018, párr. 677 ss.

[6] Ver art. 2 y 3 Ley de Amnistía; al respecto ver comentarios de Alejandro David Aponte, Título II, Capítulo I: Objeto y ámbito de aplicación, en Ley de Amnistía. Comentario completo y sistemático (Ley 1820 de 2016) (art. 2), 38-54 (art. 3), (Kai Ambos \& Gustavo Cote eds., Temis, Bogotá 2019).

[7] Ver art. 23 (parágrafo) y 46 de la Ley de Amnistía; al respecto ver Diego Fernando Tarapués Sandino, Artículo 23. Criterios de conexidad, en Ley de Amnistía. Comentario completo y sistemático (Ley 1820 de 2016), 219 -236 (Kai Ambos \& Gustavo Cote eds., Temis, Bogotá 2019); también Gustavo Emilio Cote Barco, op. cit., 439-467.

[8] Acuerdo Final de Paz, op. cit., 146 (núm. 13).

[9] Los casos abiertos por la Sala de Reconocimiento son los siguientes: Caso 01, denominado "Retención ilegal de personas por parte de las FARC-EP"; Caso 02, denominado "Situación en los municipios de Ricaurte, Tumaco y Barbacoas del Departamento de Nariño"; Caso 03, denominado "Muertes ilegítimamente presentadas como bajas en combate por agentes del Estado"; Caso 04, denominado "Situación Territorial de la región de Urabá”; Caso 05, denominado "Situación territorial en la región del norte del Cauca”; Caso 06, denominado "Victimización de miembros de la Unión Patriótica”; y Caso 07, denominado "Reclutamiento y utilización de niñas y niños en el conflicto armado". Para información general sobre el trabajo de la JEP ver www.jep.gov.co.

[10] Acuerdo Final de Paz, op. cit., 153-157 (núm. 47-48).

[11] Íd., p. 164-165 (núm. 60); también art. transitorio 25 AL 01 de 2017.

[12] Acuerdo Final de Paz, op. cit., p. 164-165 (núm. 60); ver art. 126, 127 y 141 de la Ley 1957 de 2019 o Ley Estatutaria de la JEP; al respecto ver Corte Constitucional de Colombia, Sentencia C-080 del 15 de agosto de 2018, apartado 4.1.8.4. sobre contribución a la reparación.

[13] Aunque, en este acápite no se busca discutir la viabilidad de dichos objetivos o si entre ellos son compatibles. Se trata más bien de señalar la concurrencia de distintas perspectivas y las dificultades que pueden surgir de esta circunstancia.

[14] El día 7 de marzo de 2019 se presentaron dos derechos de petición, con fundamento en el art. 23 de la Constitución Política de Colombia, tanto a la Presidencia de la Sala de Reconocimiento como a la Presidencia de la Sección de Primera Instancia para casos de reconocimiento. En estos derechos de petición se formularon varias preguntas relacionadas con la participación de las víctimas en los procesos existentes. De estos dos, el segundo no generó una respuesta sustancial (oficio del 22 de marzo de 2019). En cambio, el primero tuvo como resultado una respuesta bastante completa del Despacho de la Magistrada Julieta Lemaitre (oficio del 27 de marzo de 2019), así como de los despachos del Magistrado Iván González (oficio del 12 de abril de 2019), Nadiezdha Henriquez (oficio del 30 de abril de 2019), Oscar Parra (oficio del 13 de mayo de 2019) y Raúl Sánchez (oficio del 21 de mayo de 2019), dado que la Magistrada Lemaitre corrió traslado a estos despachos del derecho de petición presentado ante ella. Además, la Secretaría de la Sala de Reconocimiento proporcionó 
información adicional en oficio del 29 de marzo de 2019, así como la Secretaría Ejecutiva de la JEP (oficio del 30 de julio de 2019).

[15] El día 7 de marzo de 2019 se presentaron también otros dos derechos de petición, uno dirigido a la Dirección Nacional de Promoción de Derechos Humanos de la Defensoría del Pueblo y otro a la Procuraduría Delegada ante la JEP. Los dos derechos de petición generaron respuestas con información sustancial relevante, en oficio del 28 de marzo de 2019 el primero, y en oficio del 2 de abril de 2019 el segundo.

[16] En la plataforma virtual YouTube se encuentran disponibles para el público en general nueve audiencias públicas de las realizadas hasta el 17 de agosto de 2019 por la JEP, divididas en doce videos. De estas fueron observadas y analizadas las siguientes siete diligencias: (i) Audiencia de sometimiento de los ex integrantes del Estado Mayor y del Secretariado de las FARC-EP ante la Sala de Reconocimiento, realizada el 13 de julio de 2018; (ii) Audiencia de sometimiento y régimen de condicionalidad en el 'Caso Soacha' ante la Sala de Definición de Situaciones Jurídicas, realizada el 10 de agosto de 2018; (iii) Audiencia de régimen de condicionalidad a miembros del GAULA del Ejército ante la Sala de Definición de Situaciones Jurídicas, realizada el 30 de agosto de 2018; (iv) Audiencia de manifestación voluntaria de sometimiento del General ( $r$ ) del Ejército Nacional de Colombia, Mario Montoya, ante la Sala de Definición de Situaciones Jurídicas, realizada el 13 de septiembre de 2018; (v) Audiencia de régimen de condicionalidad ante la Sala de Definición de Situaciones Juridicas realizada en San Gil (Santander), 15 de noviembre de 2018; (vi) Audiencia de régimen de condicionalidad por la masacre de Mondoñedo (Cundinamarca), realizada ante la Sala de Definición de Situaciones Jurídicas el 18 de noviembre de 2018; (vii) Audiencia del coronel (r) Gabriel de Jesús Rincón Amado del Ejército Nacional de Colombia, realizada el 5 de marzo de 2019 por magistrados de la Sala de Definición de Situaciones Jurídicas junto con magistrados de la Sala de Reconocimiento. Estas diligencias están disponibles en: https://www.youtube.com/watch? v=yoKhg7c3YGQ\&list=PLbtegW3d3L4JAstPux8ji9-h9balFGI6M. También se asistió a la Audiencia de alegatos y decisión final del régimen de condicionalidad sobre 'El Paisa', realizada por la Sala de Reconocimiento el 26 de abril de 2019. Adicionalmente, de catorce videos de informes orales rendidos ante la Sala de Reconocimiento por víctimas directas o indirectas de secuestro se observaron seis, seleccionados aleatoriamente: Clara Rojas, Ingrid Betancourt, familiares de los diputados del Valle (en esta diligencia hablaron seis familiares de los diputados secuestrados y que murieron en cautiverio), Alan Jara, Luis Mendieta y Sigifredo López, ver: https://www.youtube.com/watch?v=2PD7pl68VM\&list=PLL6Y2ksUQ_KXRj39GCU3v361OPIxqoZCv

[17] Eduard Kern \& Claus Roxin, Strafverfahrensrecht, 1 (11.a ed., 1972).; Friedrich-Christian Schroeder, Strafprozeßrecht, 5-6 (C.H. Beck, 1993).

[18] Acuerdo Final de Paz, op. cit., 127.

[19] Íd., 143 (núm. 2).

[20] Íd., 144 (núm. 6)

[21] Íd.

[22] Íd.

[23] Íd.; este enfoque en los derechos de las víctimas desde el paradigma de la justicia restaurativa se encuentra también en el art. transitorio 1 (cuarto párrafo) AL 01 de 2017 y en el art. 1 (a) LP-JEP. Al respecto ver Corte Constitucional de Colombia, Sentencia C-674 de 2017, 336; Corte Constitucional de Colombia, Sentencia C-007 de 2018, párr. 111; Corte Constitucional de Colombia, Sentencia C-080 de 2018, apartado 4.1.9.

[24] La connotación penal del proceso es clara en casos de no reconocimiento de responsabilidad en la JEP, en los que se presenta una acusación y un juicio contradictorio con pleno ejercicio del derecho de defensa, ver art. 34 ss. LP-JEP.

[25] Ver III Kai Ambos, Treatise on International Criminal Law: International Criminal Procedure, 45 (Oxford University Press, 2016).

[26] Acuerdo Final de Paz, op. cit., 127.

[27] Íd.

[28] Ver supra nota 7.

[29] La Corte Constitucional ha reconocido el carácter penal de la JEP, aunque para señalar, en el marco del análisis del principio de legalidad, que este no es el único ni principal rasgo que la caracteriza. Ver Corte Constitucional de Colombia, Sentencia C-007 de 2018, párr. 398: "si bien la Jurisdicción Especial para la Paz es en cierto sentido un juez penal, no es solamente, ni principalmente, ello".

[30] Urs Kindhäuser \& Kay H. Schumann, Strafprozessrecht, 31 (5.a ed., 2019).

[31] Íd.

[32] Íd.

[33] Íd.

[34] Eduard Kern \& Claus Roxin, op. cit., 4.

[35] Urs Kindhäuser \& Kay H. Schumann, op. cit., 31; también Nandor Knust, Strafrecht und Gacaca. Entwicklung eines pluralistischen Rechtsmodell am Beispiel des ruandischen Völkernmordes, 47 (Duncker \& Humblot, 2013); sobre la 
inseparabilidad del derecho penal sustancial y procesal, ver Klaus Volk \& Armin Engländer, Grundkurs StPO, 2-3 (9. ed., C.H. Beck, 2018).

[36] Urs Kindhäuser \& Kay H. Schumann, op. cit., 31-32; también Klaus Volk \& Armin Engländer, op. cit., 3.

[37] Urs Kindhäuser \& Kay H. Schumann, op. cit., 32.

[38] Íd., 32; Klaus Volk \& Armin Engländer, op. cit., 5, sobre el debido proceso como valor en sí mismo para hacer justicia (procesal).

[39] Urs Kindhäuser \& Kay H. Schumann, op. cit., 33.

[40] Ver Corte Constitucional de Colombia, Sentencia C-080 de 2018, apartado 4.1.9. (Justicia restaurativa y sanción efectiva).

[41] Para una definición general de justicia transicional ver United Nations, Security Council, The Rule of Law and Transitional Justice in Conflict and Post-Conflict Societies, Report of the Secretary-General, 23.08.2004 (doc: S/2004/616), párr. 8; sobre la aparición de la noción de justicia transicional y su desarrollo como campo de conocimiento ver Joanna R. Quinn, The Development of Transitional Justice, en Research Handbook on Transitional Justice, 11-33 (Cheryl Lawther, Luke Moffett \& Dov Jacobs eds., 2017); también Iván Orozco, Justicia transicional en tiempos del deber de memoria (Temis-Universidad de los Andes, 2009).

[42] En este sentido Howard Zehr, Changing Lenses: A New Focus for Crime and Justice, 182 (Herald Press, 1990); también Howard Zehr \& Ali Gohar, The Little Book of Restorative Justice, 19-20 (2003).

[43] Ver Howard Zehr (1990), op. cit., 190; Howard Zehr \& Ali Gohar (2003), op. cit., 12-13.

[44] Sobre restitución ver Randy E. Barnett, Restitution. A new paradigm of criminal justice, en Restorative Justice. Critical Concepts in Criminology, 34-56 (Carolyn Hoyle Ed., Routledge, 2010).

[45] Sobre el desarrollo de este concepto, ver I Carolyn Hoyle, General Introduction, en Restorative Justice. Critical Concepts in Criminology, 1-15 (Routledge, 2010).

[46] Ver art. 521 Ley 906 de 2004; por ejemplo, sobre la conciliación en el proceso penal como mecanismo de justicia restaurativa ver Corte Constitucional de Colombia, Sentencia C-409 del 17 de junio de 2009, apartado 3.2.3; con relación a la suspensión de procedimiento a prueba y la aplicación del principio de oportunidad ver Corte Constitucional de Colombia, Sentencia C-979 del 26 de septiembre de 2005, consideración 42 ss.

[47] Con cierto escepticismo respecto de la justicia penal internacional y la dimensión que en este contexto adquiere la búsqueda de la verdad (procesal) ver Kai Ambos, op. cit, 49, 54-56; advirtiendo sobre los límites del derecho penal en contextos de justicia transicional Gerhard Werle \& Moritz Vormbaum, Transitional Justice. Vergangenheitsbewältigung durch Recht, $47-48$ (Springer, 2018).; también Christoph Safferling, Internationales Strafrecht (Springer, 2011).

[48] Similar Nandor Knust, op. cit., 52; sobre la importancia de los juicios penales en contextos de justicia transicional ver United Nations, Security Council, op. cit., párr. 39.

[49] Ver Nandor Knust, op. cit., 52.

[50] Íd.; sobre la importancia del proceso en contextos transicionales ver también Tribunal para la Paz, Sección de Apelación, Sentencia Interpretativa TP-SA-SENIT 1 de 2019, sobre beneficios provisionales, régimen de condicionalidad y participación de víctimas, 3 de abril de 2019, párr. 163. "[e]n la medida en que los relatos de dolor impacten la conciencia pública, pueden provocar una conmoción civil y política lo suficientemente intensa como para que la ciudadanía inicie un diálogo sobre las responsabilidades de distinto orden [...]".

[51] Nandor Knust, op. cit., 52.

[52] Íd., 52-53.

[53] Î́., 55-56.

[54] Íd., 53, 57; sobre la relación entre la noción de justicia transicional y la construcción de Estado de Derecho (rule oflaw) ver United Nations, Security Council, op. cit., párr. 2-4.

[55] United Nations, Security Council, op. cit., párr. 50.

[56] Íd., párr. 50; también Tribunal para la Paz, Sección de Apelación, op. cit., párr. 217 "debe esclarecer las condiciones que posibilitaron las atrocidades".

[57] Ver Gerhard Werle \& Moritz Vormbaum, op. cit., 35-36; United Nations, Security Council, op. cit., párr. 8.

[58] United Nations, Security Council, op. cit., párr. 54.

[59] Gerhard Werle \& Moritz Vormbaum, op. cit., 34-35; United Nations, Security Council, op. cit., párr. 32 y 38.

[60] Ver supra nota 46.

[61] Ver Nandor Knust, op. cit., 76.

[62] Íd., 75 ("grassroot-Ebene"), 77.

[63] Íd., 77; sobre la importancia del diálogo entre la víctima y victimario como parte de la justicia restaurativa ver Howard Zehr (2003), op. cit., 22, 44, 52, 56 y 63.

[64] Ver Nandor Knust, op. cit., 94.

[65] Entendida como la verdad constatada a través de medios de prueba racionales y/o científicos admitidos por la legislación procesal, ver Íd., 93 
[66] Entendida como la verdad del individuo, por ejemplo, de la víctima concreta, y contada por él, Íd., 94.

[67] Íd., 81-82.

[68] Ver, por ejemplo, art. 79 (i), (m) y (r), así como art. 80 Ley 1957 de 2019 o Ley Estatutaria de la JEP, sobre reconocimientos colectivos de responsabilidad ante la Sala de Reconocimiento; también art. 36 (1) LP-JEP, con relación a la presentación del escrito de acusación en casos de no reconocimiento de responsabilidad.

[69] El concepto de macrocriminalidad fue desarrollado especialmente por Herbert Jäger, quien llama la atención sobre la forma como la criminología tradicional deja de lado el estudio de formas de violencia colectiva, al concentrarse en el estudio de la criminalidad cotidiana (Alltagskriminalität). Para Jäger, fenómenos de violencia como, por ejemplo, los crímenes internacionales, no pueden explicarse desde una perspectiva individual, puesto que ellos son consecuencia -o hacen parte- de un contexto de acción colectiva (als Teil eines kollektiven Aktionszusammenhangs), en el que el comportamiento individual no representa un comportamiento desviado, sino un comportamiento conforme con la dinámica del grupo que genera la violencia, ver Herbert Jäger, Makrokriminalität: Studien zur Kriminologie kollektiver Gewalt, 11-13 (Suhrkamp Verlag 1989). En la LP-JEP este concepto aparece en los art. 11 (2), 17 (parágrafo), 18 y 36 (3).

[70] En la LP-JEP este concepto aparece en los parágrafos segundo y tercero del art. 2, en el parágrafo del art 17, y en el art. 18.

[71] Ver art 11 LP-JEP sobre los objetivos de la investigación criminal en este contexto; también parágrafo del art 17 LPJEP y art 36 (3) LP-JEP. En respuesta al derecho de petición presentado el 7 de marzo de 2019 (ver supra nota 14), la Procuraduría Delegada para la JEP explicó el concepto de macrovictimización de la siguiente manera: "[es] aquella forma de victimización causada en escenarios de violaciones masivas y sistemáticas de derechos, en los que la reparación debe tener una visión colectiva, con enfoques diferenciales, territoriales y que permitan recuperar las formas de vida de las poblaciones en condición de vulnerabilidad [...] se vincula con los fenómenos de macrocriminalidad, en los cuales tanto la persecución individual de los delitos y la reparación individual se traduce en impunidad e insatisfacción de facto debido a la imposibilidad de investigar y juzgar cada uno de los delitos causados" (Concepto No. 019-2019-6CHC-1IJP del 2 de abril de 2019, 4). Esta idea también da lugar a la representación judicial colectiva de víctimas en los procesos con reconocimiento de responsabilidad ante la JEP, tal y como lo dispone el art. 2 (iv) y el parágrafo segundo del mismo art. 2 de la LP-JEP. Según la respuesta dada el 30 de julio de 2019 por la Secretaría Ejecutiva de la JEP (Oficio No. 201961220349981) al derecho de petición presentado el 7 de marzo de 2019 (ver supranota 14), para la fecha de la respuesta se habían dado tres solicitudes para el nombramiento de representante colectivo de víctimas, en los casos 01 , 03 y 07 , lo cual obedece a que "se trata de procesos con un universo de víctimas muy amplio".

[72] Con relación al componente restaurativo de la sanción propia, ver el listado de sanciones previsto en el art. 141 de la Ley 1957 de 2019 (Estatutaria de la JEP), dentro del cual se incluyen, por ejemplo, "[p]articipación/[e]jecución de programas de protección medio ambiental de zonas de reserva", "[p]articipación/[e]jecución de programas de construcción y reparación de Infraestructuras en zonas rurales: escuelas, carreteras, centros de salud, viviendas, centros comunitarios, infraestructuras de municipios, etc.” y “[p]articipación/[e]jecución de programas de desarrollo rural”.

[73] Ver supra nota 23.

[74] Ver art. 1 (b) y 27 de la LP-JEP.

[75] Ver art. 73 de la Ley 1957 de 2019 o Ley Estatutaria de la JEP: "En la JEP se aplicarán dos procedimientos:1. Procedimiento en caso de reconocimiento de verdad y reconocimiento de responsabilidad. 2. Procedimiento en caso de ausencia de reconocimiento de verdad y de responsabilidad".

[76] Acuerdo Final de Paz, op. cit., 153 (núm. 47) - 154 (núm. 48), 161 (núm. 53), 1164-165 (núm. 60).

[77] Íd.

[78] Íd., 159 (núm. 51), 160 (núm. 62), 162 (núm. 64), 165.

[79] El art. 1 (b) LP-JEP define de la siguiente manera el carácter dialógico del proceso: “[e]l procedimiento en casos de reconocimiento de la verdad tendrá un carácter dialógico o deliberativo, con participación de las víctimas y de los comparecientes a la JEP [...] Se aplicará de preferencia el principio dialógico sobre el adversarial, respetando y garantizando en todo caso los principios de imparcialidad, independencia judicial, debida motivación, publicidad, debido proceso, contradicción, derecho a la defensa, presunción de inocencia, favorabilidad, libertad de escoger profesional del derecho con acreditación [...] participación de las víctimas y doble instancia [...]".

[80] Definición extraída del Diccionario de la Real Academia de la Lengua Española (RAE. Según el art. 28 del Código Civil colombiano "[1] as palabras de la ley se entenderán en su sentido natural y obvio, según el uso general de las mismas palabras; pero cuando el legislador las haya definido expresamente para ciertas materias, se les dará en éstas su significado legal". Dado que en este contexto no existe una definición legal específica de deliberar, la definición de la RAE es de utilidad.

[81] Ver supra nota 12.

[82] De acuerdo con el parágrafo del art. 27 LP-JEP: "La Sala de Reconocimiento de Verdad y Responsabilidad y Determinación de los Hechos y Conductas incluirá en la Resolución de Conclusiones el proyecto de sanciones con su contenido reparador y de medidas restaurativas que podrán ser definidas con participación de las víctimas”. 
[83] Ver art. 27 LP-JEP ("promoverán la construcción de acuerdos aplicando criterios de razonabilidad y proporcionalidad"); sobre el principio dialógico, entendido como construcción de acuerdos, ver Tribunal para la Paz, Sección de Apelación, op. cit., párr. 166 ("participación en diálogos o interacciones") y 210 ("construcción colectiva con miras al logro de un propósito común").

[84] Acuerdo Final de Paz, op. cit., 154 (núm. 48, b, c, d, e).

[85] Para facilitar la presentación de informes la JEP publicó en su página web el documento Orientaciones para la presentación de informes; según informó el 29 de marzo de 2019 la Secretaría de la Sala de Reconocimiento (Oficio No. OSJSRVR-01033), en respuesta al derecho de petición del 7 de marzo de 2019 (ver supra nota 14), para la fecha del oficio aquí mencionado las organizaciones de víctimas habían presentado un total de 72 informes, de los cuales 33 hacen parte de los casos ya existentes y se distribuyen de la siguiente manera (p. 2-3): Caso 01, 7 informes; Caso 02, 9 informes; Caso 03, 12 informes; Caso 04, 3 informes; Caso 05, 2 informes; Caso 06, 1 informe; Caso 07, 1 informe (aunque existen informes que se refieren a varios casos, como ocurre con dos informes presentados en los casos 02 y 05 ).

[86] Ver art. $27 \mathrm{~A}$.

[87] Íd.

[88] Íd.

[89] Íd.

[90] De acuerdo con el art. 27 B LP-JEP: "La Sala contrastará los informes con el acervo probatorio y después de haber tenido en cuenta las versiones voluntarias de que trata el artículo anterior, en caso de apreciar que existen bases suficientes para entender que la conducta existió, que la persona participó y que la conducta pertenece a tipos penales no amnistiables, deberá ponerlos a disposición de los presuntos responsables para que tomen la decisión de comparecer o no a efectuar el aporte de verdad y reconocimiento, o a defenderse de las imputaciones formuladas".

[91] Parágrafo 1, art. 19 LP-JEP.

[92] Ver art. $27 \mathrm{~B}$.

[93] Íd.

[94] ¿Qué pasa entonces con las víctimas directas o indirectas que quieran participar por sí mismas o a través de un apoderado propio en esta diligencia? o ¿podrían participar, por iniciativa propia, organizaciones de víctimas no invitadas?

[95] Ver JEP, Sala de Reconocimiento de Verdad, de Responsabilidad y de Determinación de los Hechos y Conductas, Auto 080 del 28 de mayo de 2019, párr. 70 ss.

[96] Íd., ver art. $27 \mathrm{D}$.

[97] Íd., núm. 4.

[98] Íd., núm. 5.

[99] Si el compareciente niega ser responsable de alguno de los crímenes documentados por la Sala de Reconocimiento, el proceso también continúa ante el Tribunal para la Paz, pero ante la Sección de Primera Instancia para casos de Ausencia de Reconocimiento; ver art. 34 y ss. LP-JEP.

[100] Ver art 13 LP-JEP.

[101] De acuerdo con el art 28 LP-JEP, "[r]ecibida la resolución de conclusiones, la Sección de Reconocimiento de Verdad y Responsabilidad del Tribunal, realizará el reparto del caso a uno de los Magistrados de la Sección, quien actuará como ponente. El Magistrado Ponente, mediante resolución que será emitida dentro de los tres días siguientes al reparto, comunicará a la Sala de Reconocimiento de verdad y Responsabilidad, como también a los sujetos procesales y a los intervinientes, que la Sección asume competencia”.

[102] Ver art. 29: "[...] determinará la correspondencia entre los hechos, las conductas reconocidas, las pruebas allegadas, las calificaciones realizadas, los responsables, la propuesta de la sanción [...]”.

[103] Según el art 29 LP-JEP, "[e]l Magistrado Ponente, dentro de los treinta (30) días siguientes, efectuará el estudio preliminar de la resolución de conclusiones y sus anexos; vencido este término, presentará a la Sección su informe preliminar, donde se discutirá el enfoque y si se hace necesario se orientará el estudio, en un término máximo de noventa

[104] Íd. (90) días para presentación de la ponencia”.

[105] Íd.

[106] Íd.

[107] Según el art 29 LP-JEP: "se determinará la correspondencia entre los hechos, las conductas reconocidas, las pruebas allegadas, las calificaciones realizadas, los responsables, la propuesta de la sanción, analizando las condiciones de contribución a la verdad y reparación en el marco del SIVJRNR".

[108] Ver art. 30 LP-JEP.

[109] Íd.

[110] Íd. 
[111] Según el art. 31 LP-JEP, la finalidad de esta audiencia es "conocer la metodología empleada en la elaboración de la resolución, ampliar sus explicaciones, complementar la resolución, absolver preguntas sobre las conductas reconocidas, los responsables, la propuesta de sanciones".

[112] Íd.

[113] En este sentido podría traerse a colación la siguiente consideración hecha por la Sección de Apelación del Tribunal ara la Paz: "La omisión en materia de diseño [...] incide, entre otras esferas, en el debilitamiento y marchitamiento de los procedimientos dialógicos”, ver Tribunal para la Paz, Sección de Apelación, op. cit., párr. 120.

[114] Ver supra notas 20, 22, 23, 24, 80 y 83.

[115] Ver supra nota 76.

[116] Ver JEP Colombia, Audiencia del coronel (r) Gabriel de Jesús Rincón Amado del Ejército Nacional de Colombia, realizada por magistrados de la Sala de Definición de Situaciones Jurídicas junto con magistrados de la Sala de Reconocimiento el 5 de marzo de 2019. YouTube.

[117] Este compareciente fue condenado en la justicia penal ordinaria por los delitos de desaparición forzada agravada (art. 180 y $191 \mathrm{CP}$ ), homicidio agravado (art. 103 y $104 \mathrm{CP}$ ) y concierto para delinquir agravado (art. $340 \mathrm{CP}$ ).

[118] Ver art. 46 LA.

[119] Para conocer los antecedentes de la diligencia ver Audiencia del coronel (r) Gabriel de Jesús Rincón Amado, op. cit., min. 00:29.55 ss.

[120] Íd.

[121] Íd.

[122] Íd., min. 00:50 ss.

[123] Íd.

[124] Ver art. 6 LA.

[125] Por régimen de condicionalidad se entiende la imposición de condiciones, orientadas a asegurar la contribución del compareciente a la satisfacción de los derechos de las víctimas y la no repetición, y así recibir y mantener los tratamientos penales especiales procedentes en el contexto de la JEP. Este régimen implica el control y seguimiento que ejercen los órganos de la JEP con relación al posible cumplimiento o no de dichas condiciones; ver art. 67-69 LP-JEP; también Corte Constitucional de Colombia, Sentencia C-007 de 2018, párr. 695 ss.

[126] Ver JEP Colombia, Audiencia de sometimiento y régimen de condicionalidad en el 'Caso Soacha' ante la Sala de Definición de Situaciones Jurídicas, realizada el 10 de agosto de 2018. YouTube.

[127] Íd., min. 05:18.30 ss.

[128] Íd.

[129] Íd.

[130] Íd.

[131] Íd.

[132] Íd.

[133] Íd.

[134] Íd.

[135] En este sentido son ilustrativas las fases del proceso de priorización que lleva a cabo la Sala de Reconocimiento, para la construcción de sus casos. Según se explica en el Oficio No. 20193210194011 del 13 de mayo de 2019 (p. 3-4), mediante el cual el presidente de la Sala de Reconocimiento para esa fecha, Magistrado Oscar Parra, respondió al derecho de petición presentado el 7 de marzo del mismo año (ver supra nota 14), este proceso se compone de tres partes: agrupación, concentración y priorización. Precisamente, en la etapa de agrupación la Sala debe "construir y delimitar universos provisionales de casos", podría agregarse, individuales, para pasar posteriormente a identificar tanto patrones de macrocriminalidad, como posibles responsables. En el Caso 003 este proceso ha revestido una especial complejidad, dado que, según se explica en el oficio aquí mencionado, más del 90\% de los miembros de la Fuerza Pública que han comparecido ante la JEP, al parecer, están implicados en hechos relacionados con "muertes ilegítimamente presentadas como bajas en combate". Sobre la estrategia de priorización de la Sala de Reconocimiento ver el documento, elaborado por la Sala, Criterios y metodología de priorización de casos y situaciones, del 28 de junio de 2018.

[136] Ver supra nota 120.

[137] Íd.

[138] Íd., min. 01:02.55 ss.

[139] Íd., min. 00:33.26 ss.

[140] Ver Audiencia del coronel (r) Gabriel de Jesús Rincón Amado, op. cit., min. 00:45.45 ss.

[141] Ver supra nota 96.

[142] Ver Audiencia del coronel (r) Gabriel de Jesús Rincón Amado, op. cit., min. 00:45.45 ss.

[143] Íd. 
[144] Así se informó en respuesta al derecho de petición presentado el 7 de maro de 2019 ante el despacho de la Magistrada Julieta Lemaitre (ver supra nota 14). Esta respuesta se encuentra en Oficio No. SRVR-00325 del 27 de marzo del mismo año.

[145] Ver JEP Colombia, Audiencia de sometimiento de los ex integrantes del Estado Mayor y del Secretariado de las FARC-EP ante la Sala de Reconocimiento parte 1 y parte 2, realizada el 13 de julio de 2018. YouTube.

[146] Ver supra nota 16.

[147] El papel que juegan los magistrados en la realización del principio dialógico en la dinámica de las audiencias ha sido reconocido por la Sección de Apelación del Tribunal para la Paz al afirmar, con relación a la Sala de Definición de Situaciones Jurídicas, que esta: "promoverá el diálogo para profundizar el enfoque restaurativo y transformador que se le otorga a este escenario en la JEP, con miras al fortalecimiento de los compromisos de verdad, reconciliación, reparación y no repetición", ver Tribunal para la Paz, Sección de Apelación, op. cit., párr. 160.

[148] Aunque la labor pedagógica de los magistrados y magistradas no se ha limitado a lo que ocurre en las diligencias judiciales, ya que también se ha emprendido la labor de realizar encuentros por fuera de lo estrictamente procesal. Así ha sucedido, por ejemplo, en el marco del Caso 003, en donde se han llevado a cabo reuniones con autoridades indígenas y grupos de víctimas. Así se informó en la respuesta dada por el Magistrado Oscar Parra al derecho de petición presentado el 7 de marzo de 2019 (ver supra nota 136), en el que se menciona un encuentro con autoridades de los pueblos indígenas Kankuamo y Wiwa los días 19 y 20 de 2018, así como un encuentro con 70 víctimas realizado el 15 de diciembre de ese mismo año y otro con un grupo de 52 víctimas realizado los días 14 y 15 de diciembre, también de 2018.

[149] Ver, por ejemplo, Audiencia del coronel (r) Gabriel de Jesús Rincón Amado, op. cit., min. 00:38.00 ss. y min. 00:48.40 ss.; Audiencia de sometimiento y régimen de condicionalidad en el 'Caso Soacha', op. cit., min. 01:39.00 ss. y 05:18.39 ss.; JEP Colombia, Audiencia de régimen de condicionalidad por la masacre de Mondoñedo (Cundinamarca), Mondoñedo I, realizada ante la Sala de Definición de Situaciones Jurídicas el 18 de noviembre de 2018, primera parte. YouTube. min. 00:57.10 ss.

[150] Ver, por ejemplo, Audiencia de sometimiento de los ex integrantes del Estado Mayor y del Secretariado de las FARC-EP ante la Sala de Reconocimiento, partes 1 y 2, op. cit.; también JEP Colombia, Audiencia de manifestación voluntaria de sometimiento del General ( $r$ ) del Ejército Nacional de Colombia, Mario Montoya, ante la Sala de Definición de Situaciones Jurídicas, realizada el 13 de septiembre de 2018. YouTube.

[151] Sobre todo, en los informes orales que rindieron algunas víctimas en el caso 001, ver supra nota 16.

[152] Ver, por ejemplo, JEP Colombia, Audiencia de régimen de condicionalidad a miembros del GAULA del Ejército ante la Sala de Definición de Situaciones Juridicas, realizada el 30 de agosto de 2018. YouTube, min. 1:21.00 ss., momento en el que la Magistrada explica el objetivo de la audiencia y las características del régimen de condicionalidad, y min 2:33.00 ss., momento en el que la Magistrada explica a los comparecientes porqué no es procedente la suspensión de procesos en la justicia ordinaria; también JEP Colombia, Audiencia de régimen de condicionalidad ante la Sala de Definición de Situaciones Juridicas, realizada en San Gil (Santander), 15 de noviembre de 2018. YouTube, min. 00:37.38 ss., momento en el que la Magistrada se refiere al carácter pedagógico que pueden o deben tener estas audiencias y se hace alusión al enfoque dialógico, y min. 01:07.48 ss., momento en el que la Magistrada, haciendo alusión nuevamente al carácter pedagógico y dialógico, explica el alcance de los compromisos que corresponden al régimen de condicionalidad.

[153] Ver, por ejemplo, JEP Colombia, Informe oral presentado por Ingrid Betancourt ante la Sala de Reconocimiento. YouTube, min. 1:58.49, momento en el cual uno de los magistrados indaga sobre estrategias de resistencia personal; también la declaración de Diego Beltrán en: JEP Colombia, Informes orales de familiares de Diputados del Valle. YouTube, min. 00:55.00, momento en el cual se narran aspectos biográficos y familiares de la víctima directa que falleció en cautiverio.

[154] Así sucedió, por ejemplo, en la JEP Colombia, Audiencia de alegatos y decisión final del régimen de condicionalidad sobre 'El Paisa', realizada por la Sala de Reconocimiento el 26 de abril de 2019. YouTube, en la que la defensa y la Procuraduría General de la Nación presentaron alegatos e interpusieron recursos para defender posiciones contrarias sobre la decisión de la Sala respecto a la permanencia del compareciente en la JEP. Esta audiencia tuvo una dinámica adversarial -en sentido tradicional-, aunque su realización, según explicó la Magistrada que la presidía, se justificó en el principio dialógico, dado que, como lo sugirió la Magistrada, la Sala se hubiera podido conformar con la presentación por escrito de alegatos, lo que ocurrió antes de la diligencia.

[155] Ver, por ejemplo, Audiencia de sometimiento y régimen de condicionalidad en el 'Caso Soacha', op. cit., min. 01:59.00 ss., momento a partir del cual catorce comparecientes manifiestan o reiteran su voluntad de someterse a la JEP y aluden a los compromisos de verdad y reparación para con las víctimas, también min. 04:52.40 ss., momento a partir del cual intervienen algunos representantes de víctimas, manifestando preocupaciones y expectativas frente al proceso.

[156] Ver, por ejemplo, Audiencia del coronel (r) Gabriel de Jesús Rincón Amado, op. cit., min. 01:11.11 ss., momento en el que una de las víctimas indirectas se dirige al compareciente, para pedirle que aporte algo más de lo que hasta el momento les han dicho y les diga la verdad sobre porqué cometieron los crímenes, también min. 01:17.40, momento en el que otra víctima indirecta se dirige al compareciente para pedir información sobre máximos responsables, y min. 01:21.29, momento en el que el compareciente responde a las víctimas y reitera su compromiso de aportar verdad plena; Audiencia 
de régimen de condicionalidad realizada en San Gil (Santander), op. cit., min. 00:55.50 ss. (uno de los comparecientes pide perdón a las víctimas) y min. 01:12.05 ss. (una de las víctimas, en nombre propio y representando a las demás, acepta las disculpas del compareciente); Audiencia de régimen de condicionalidad a miembros del GAULA, op. cit., min. 03:19.14 ss. (intervención de compareciente en la que expresa su compromiso frente a las víctimas y la JEP, solicita comparecer ante la Sala de Reconocimiento y, dirigiéndose a las víctimas, les pide perdón y ofrece reconocer, tal como ellas lo han pedido, que sus familiares no eran combatientes ni delincuentes, y trabajar por el restablecimiento de su buen nombre), min. 03:37.20 ss. (compareciente también se dirige a las víctimas para manifestar arrepentimiento), y min. 03:47.10 (intervención bastante emotiva de víctima indirecta manifestando su dolor).

[157] Ver supra notas 80 y 81, así como el correspondiente texto principal.

[158] Ver Audiencia de sometimiento y régimen de condicionalidad en el 'Caso Soacha', op. cit., min. 01:42.50 ss.; Audiencia del coronel (r) Gabriel de Jesús Rincón Amado, op. cit., min. 00:33.20.

[159] Ver supra notas 23 y 24.

[160] Ver Acuerdo Final de Paz, op. cit., p. 146 (núm. 13); también art. transitorio 5 AL 01 de 2017 (párrafo octavo) y art. 20 Ley Estatutaria de la JEP.

[161] Ver Audiencia de sometimiento y régimen de condicionalidad en el 'Caso Soacha', op. cit., min. 01:46.05.

[162] Ver Audiencia del coronel (r) Gabriel de Jesús Rincón Amado, op. cit., min. 00:53.00.

[163] Ver Audiencia de sometimiento y régimen de condicionalidad en el 'Caso Soacha', op. cit., min. 04.52.50.

[164] Íd.

[165] Íd., min. 05:09.30 ss.

[166] Íd., min. 05:15.30 ss.; también Audiencia del coronel (r) Gabriel de Jesús Rincón Amado, op. cit., min. 01:17.50 ss.

[167] Algunas de las afirmaciones hechas por Ingrid Betancourt al rendir informe oral ante la Sala de Reconocimiento permiten ilustrar la importancia de la verdad como forma de reparación de las víctimas, ver Informe oral presentado por Ingrid Betancourt ante la Sala de Reconocimiento, op. cit., min. 00:10.00 ss. ("la relación que tenemos con la verdad es fundacional, la verdad nos reconstruye [...] la verdad es la que nos libera, es la que nos pone en armonía con el mundo y con el entorno".

[168] Algunas referencias a la responsabilidad de los altos mandos de las FARC en los secuestros se encuentran en el Informe oral presentado por Ingrid Betancourt ante la Sala de Reconocimiento, op. cit., min. 01:39.25; también en la declaración de Ángela Giraldo, en: Informes orales de familiares de Diputados del Valle, op. cit., min. 00:32.26 (pidiendo que se haga justicia sobre los máximos responsables); también en el Informe oral de Luis Mendieta ante la Sala de Reconocimiento, min. 00:29.00 (afirmando que las cabecillas responsables de su cautiverio tenían comunicación con el Secretariado de las FARC).

[169] Ver declaración de Juliana Orozco, en: Informes orales de familiares de Diputados del Valle, op. cit., min. 01:52.00 ss., en donde afirma que le interesa conocer la verdad completa, pero que para esto es más importante dialogar con quienes cuidaban en el día a día a su padre y no con los jefes.

[170] Ver Informe oral presentado por Ingrid Betancourt ante la Sala de Reconocimiento, op. cit., min. 00:18.00 ss.; JEP Colombia, Informe oral de Clara Rojas ante la Sala de Reconocimiento. YouTube, min. 00:21.00 ss.

[171] Ver Informes orales de familiares de Diputados del Valle, op. cit., min. 00:19.00, 00:42.00, 01:48.40, en donde se plantean cuestionamientos al Estado debido a la negativa del Gobierno a negociar un intercambio humanitario y a la negativa del Tribunal Administrativo del Valle a reconocer en este caso la responsabilidad administrativa del Estado con fundamento en la falla del servicio.

[172] En los informes orales de víctimas de secuestro en el caso 001 la Sala de Reconocimiento ha preguntado a las personas que acudieron a ella cómo imaginan la sanción propia; varias de las formas de reparación aquí mencionadas han sido planteadas al contestar dicha pregunta.

[173] Ver Informes orales de familiares de Diputados del Valle, op. cit., min. 02:29.45.

[174] Íd.., min. 01:54.30 ss.

[175] Ver Audiencia de sometimiento y régimen de condicionalidad en el 'Caso Soacha', op. cit., min. 05:11.30.

[176] Ver declaraciones de Diego Barragán y Fabián Arismendi, en: Informes orales de familiares de Diputados del Valle, op. cit., min. 01:09.00 ss. y 02:15.00, haciendo referencia a los encuentros con miembros de las FARC que tuvieron lugar durante el proceso de paz.

[177] Ver supra nota 170.

[178] Ver Audiencia de sometimiento y régimen de condicionalidad en el 'Caso Soacha', op. cit., min. 04:59.40 ss., momento en el que una representante de víctimas hace referencia al "trabajo mancomunado" entre víctimas y comparecientes que supone el principio dialógico.

[179] Íd., min. 03:34.00 ss.

[180] Ver Audiencia de régimen de condicionalidad por la masacre de Mondoñedo (Cundinamarca), Mondoñedo I, op. cit., min. 00:04.00 ss. y 00:51.20 ss. 
[181] Ver JEP Colombia, Audiencia de régimen de condicionalidad, Mondoñedo II, realizada ante la Sala de Definición de Situaciones Jurídicas el 28 de noviembre de 2018. YouTube.

[182] Íd.

[183] Ver JEP Colombia, Audiencia de régimen de condicionalidad, Mondoñedo III, realizada ante la Sala de Definición de Situaciones Jurídicas el 28 de noviembre de 2018. YouTube.

[184] Ver supra notas 69 a 75, así como el texto principal correspondiente.

[185] Ver supra nota 55.

[186] Ver supra notas 19, 27 y 28.

[187] Ver supra notas 91, 93 y 94.

[188] Ver supra nota 103.

[189] Ver supra notas 93 a 95, así como el correspondiente texto principal.

[190] Ver supra nota 50, así como el correspondiente texto principal.

[191] Ver supra nota 137 y 138.

[192] Ver supra notas 141 y 143.

[193] Ver supra nota 16.

[194] Ver supra notas 56 a 60, así como el correspondiente texto principal.

[195] En este sentido resulta ilustrativo lo dicho por la Sección de Apelación del Tribunal para la Paz sobre la preponderancia de la participación colectiva de las víctimas: "[l]a estricta temporalidad de la JEP, en conjunto con los principios constitucionales anotados, exigen de ella un despliegue funcional que, sin desatender los principios de respeto por los derechos individuales, no complique en exceso los trámites y evite, cuando ello sea posible, prolongar los tiempos procesales. La participación colectiva es, precisamente, un mecanismo dinamizante que puede conseguir esos objetivos", ver Tribunal para la Paz, Sección de Apelación, op. cit., párr. 110. Para esto, la Sección de Apelación se basa en lo dicho por la Corte Constitucional sobre la Ley Estatutaria de la JEP, ver Corte Constitucional de Colombia, Sentencia C-080 de 2018. Al respecto también supra nota 72.

[196] Ver supra notas 70 y 71.

[197] Ver supra notas al pie 23 y 57.

[198] Según se informó en la respuesta dada por el Magistrado Oscar Parra el 13 de mayo de 2019 (ver supra nota 136) al derecho de petición presentado el 7 de marzo del mismo año (ver supra nota 14), para el 13 de marzo de 2019, en este caso 71 personas habían rendido versión voluntaria, mientras que el total de comparecientes que pertenecen a las unidades militares priorizadas en este era de 917; sin embargo, al respecto se aclara que el número total de comparecientes en el Caso 003 asciende aproximadamente a 2000 personas (p. 6-7); en este mismo caso se habían acreditado 163 víctimas.

[199] Según se informó en respuesta dada por la Magistrada Nadiezdha Henriquez el 30 de abril de 2019 (Oficio No. 20193240172781) al derecho de petición presentado el 7 de marzo del mismo año (ver supra nota 14), al momento de avocar conocimiento en el Caso 004, denominado "Situación territorial de la región de Urabá", se tenía noticia de 787.000 víctimas registradas en la Dirección Territorial del Urabá de la Unidad para la Atención y Reparación Integral a las Víctimas, también se habían identificado 3523 hechos y 174 comparecientes relacionados con al menos 221 víctimas (p. 8). Para la fecha de la respuesta al derecho de petición, se habían presentado dos solicitudes de acreditación de víctimas, una individual y otra colectiva que involucraba 600 personas (p. 11), y habían individualizado al menos 501 presuntos perpetradores (p. 15).

* Artículo de investigación. Este artículo hace parte del proyecto de investigación Implementación del Estatuto de Roma en Colombia: encuentros y divergencias entre el derecho penal nacional y el internacional, el cual se enmarca en la línea sobre Derecho Penal y Criminología del grupo de investigación en Justicia Social, Teoría Jurídica General y Teoría Política, de la Facultad de Ciencias Jurídicas de la Pontificia Universidad Javeriana de Bogotá. El autor agradece a Julieta Olarte Espitia, Daniela Franco Hernández y Alejandra López, estudiantes de Derecho de la Pontificia Universidad Javeriana, quienes participaron como asistentes de investigación en la recopilación y sistematización de información relevante. También agradece a los/as magistrados/as de la Sala de Reconocimiento de Responsabilidad, así como a los demás funcionarios de la JEP, de la Procuraduría General de la Nación y de la Defensoría del Pueblo que atendieron a los derechos de petición presentados con el objetivo de obtener insumos para la elaboración del texto.

\section{Licencia Creative Commons CC BY 4.0}

Cómo citar este artículo: Gustavo Emilio Cote Barco, El carácter dialógico del proceso con reconocimiento de responsabilidad ante la Jurisdicción Especial para la Paz: retos del derecho penal en contextos de justicia transicional, 69 Vniversitas (2020). https://doi.org/10.11144/Javeriana.vj69.cdpr 